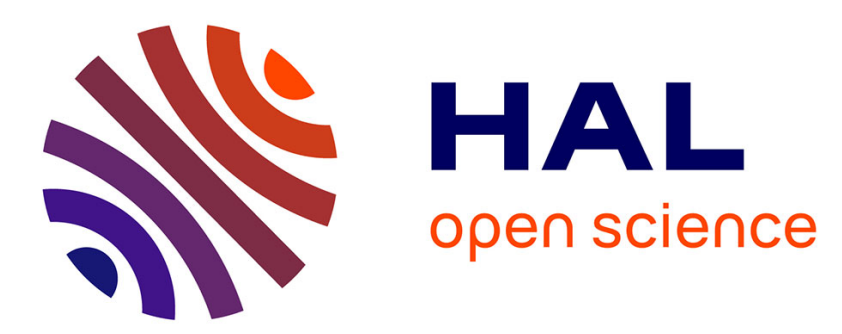

\title{
Microscopic mechanism of particle detachment in granular materials subjected to suffusion in anisotropic stress states
}

Qirui Ma, Antoine Wautier, Wei Zhou

\section{- To cite this version:}

Qirui Ma, Antoine Wautier, Wei Zhou. Microscopic mechanism of particle detachment in granular materials subjected to suffusion in anisotropic stress states. Acta Geotechnica, 2021, 16 (8), pp.25752591. 10.1007/s11440-021-01301-x . hal-03462102

\section{HAL Id: hal-03462102 \\ https://hal.inrae.fr/hal-03462102}

Submitted on 1 Dec 2021

HAL is a multi-disciplinary open access archive for the deposit and dissemination of scientific research documents, whether they are published or not. The documents may come from teaching and research institutions in France or abroad, or from public or private research centers.
L'archive ouverte pluridisciplinaire $\mathbf{H A L}$, est destinée au dépôt et à la diffusion de documents scientifiques de niveau recherche, publiés ou non, émanant des établissements d'enseignement et de recherche français ou étrangers, des laboratoires publics ou privés. 


\title{
Microscopic mechanism of particle detachment in granular materials subjected to suffusion in anisotropic stress states
}

\author{
Qirui Ma ${ }^{1,2}$, Antoine Wautier ${ }^{2 *}$, Wei Zhou ${ }^{1 *}$ \\ 1. State Key Laboratory of Water Resources and Hydropower Engineering Science, Wuhan \\ University, 430072, Wuhan, China. \\ 2. INRAE Aix-Marseille University, UMR RECOVER, 3275 Rte Cézanne, CS 40061, 13182 Aix- \\ en-Provence Cedex 5, France. \\ *Corresponding authors: Antoine Wautier (antoine.wautier@inrae.fr); Wei Zhou \\ (zwmxx@,whu.edu.cn)
}

Abstract: Suffusion refers to a special form of internal erosion characterized by the selective erosion of the finest particles of a soil under the action of an internal fluid flow. In this work, the microscopic mechanism of particle detachment in binary mixtures subjected to suffusion under different flow directions is analyzed. We use the coupled lattice Boltzmann method (LBM) and discrete element method (DEM) to simulate the suffusion process in a granular sample subjected to an anisotropic stress state. When the macro flow direction is aligned with the principal direction of compression, it is found that the fluid flow is more intense, which increases erosion. The stress anisotropy also influences the detachment direction that is not necessarily correlated with the macroscopic flow direction. The sample's anisotropic stress state is responsible for directional variations in microstructural properties during the suffusion under different flow directions. From a micro scale point of view, a contact sliding index $P$ and a particle detachment index $\Delta$ are defined to demonstrate that fluid-induced sliding dominates for particles about to detach. 
Keywords: Suffusion, LBM-DEM, Detachment mechanism, Anisotropic stress, Particle migration

\section{Introduction}

Suffusion refers to one of the typical phenomena of internal erosion, which consists of interaction between particles and seepage flow. This phenomenon can be described as the process of detachment and transport of the finest particles within the porous medium formed by coarse particles [1]. In geotechnical engineering, this complex phenomenon leads to loss of soil mass and non-negligible modifications in the constitutive behavior of soils. Such modification of the soil is one of the most common reasons for failure in dams, roads, and railways [2][3][4]. In the field of embankment dams and levees, about $50 \%$ of total failures originated from different forms of internal erosion [5][6]. However, the development process of internal erosion phenomena such as suffusion, which occurs inside the soil structure, lacks of direct observations and is poorly documented and understood. At the scale of hydraulic structures, visible signs of internal erosion are often detected long after it initiates and frequently too late to prevent a subsequent collapse of the structure [7]. Therefore, the serious consequences of internal erosion of hydraulic structures and its unobservable characteristics at the macro-scale emphasize the importance of a comprehensive understanding of suffusion phenomena including particle separation and transportation.

The initial research on internal erosion dates back from Terzaghi's criterion for heave, which relates erosion damage to the critical hydraulic gradient corresponding to the vanishing of the effective mean stress [7]. Since then, many studies have been 
conducted to understand the mechanism of internal erosion, especially the relationship between the critical hydraulic gradient and soil properties [8][9]. However, the onset and continuation of suffusion are influenced by a series of factors including material susceptibility [10][11][12], stress state [13][14], and hydraulic conditions [15][16]. Extensive experimental tests have been carried out to study internal stability (i.e. material susceptibility ${ }^{1}$ ) and critical hydraulic gradient in internal erosion [2][17][18][19]. Moffat et al.[20] conducted laboratory tests to study the spatial and temporal progression of internal erosion in cohesionless soils. The influence of confining pressure on internal erosion has also been examined via stress-controlled testing apparatus [21]. The reduction of the soil strength with suffusion was observed when the soil sample experience a monotonic compression test [22]. But there are also several studies showing that the eroded soil samples may demonstrate stronger resistance against liquefaction and stronger undrained shear strength [23][24]. With advanced techniques such as micro-CT and plane laser-induced fluorescence (PLIF), the visualization of suffusion phenomenon can be obtained during experimental tests [25][26]. Such experimental investigations of suffusion enriched the understanding of the phenomenon, but the lack of high resolution in devices and migration characteristics of suffusion, the micromechanical particle detachment and transportation process during suffusion is hard to detect in laboratory tests. In addition, some scholars have carried out a series of studies on internal erosion from the perspective of poromechanics,

\footnotetext{
1 Internal stability is defined as the sensitivity of a material to suffusion. No systematic link has been established between internal instability and mechanical instability.
} 
resulting in the proposal of several extend constitutive models reflecting internal erosion directly at macro continuum scale [27][28][29].

With the development of particle scale simulation and high-performance parallel computing technology, numerical modeling provides a feasible method to simulate the suffusion process at a much elementary scale and gain knowledge related to the basic mechanism of suffusion. The discrete element method (DEM) has significant advantages in tracing the information of every single particle [30]. When applied to suffusion simulation, the fine particle removal methods were first used to mimic the process in pure DEM simulation without accounting for the fluid phase [31][32][33]. This selective removal approach is however not able to reproduce realistic microstructure modifications during seepage induced suffusion, and in particular the modifications of the pore space resulting from the displacements and clogging of free particles. In addition, the soil fabric generated by this procedure may be sensitive to the frequency and rate of the removal algorithm that does not necessarily reflect the rate imposed by an internal fluid flow. Artificial removal of grains can artificially affect the stress-strain response as well as the final gradation distribution of eroded samples [32]. Therefore, the fluid phase was introducing into the simulations by solid-fluid coupling methods in recent years [34][35]. The coupled computational fluid dynamics and discrete element method (CFD-DEM) was widely used to study internal erosion $[36][37][38][39][40][41][42]$, but the pore space complex geometry is frequently averaged by using unresolved scheme for the fluid. Kawano et al. [43] analyzed the initiation of suffusion with varying fines content and relative density in gap-graded 
samples. Suffusion-induced deformation and mechanical change in granular soils were investigated by Hu et al. [44][45]. Coupled Pore scale Finite Volumes and DEM (PFVDEM) is another numerical way to solve the interaction between solid and fluid [46] through a resolved but approximated approach. Wautier et al. [47][48] adopted this method to explored particle transport, flow impact on granular force chains and induced mechanical instability during suffusion. Different from other traditional fluid phase solvers, the lattice Boltzmann method (LBM) was revealed to be equivalent to a finite difference approximation to Navier-Stokes equations for incompressible fluids [49][50], which can be coupled with DEM through the immersed moving boundaries [51][52]. The three-dimensional LBM-DEM has been adopted in the soil erosion in granular filters [53] and suffusion in binary mixtures [54]. This approach is spatially resolved and is able to take into account the full complexity of the pore space geometry.

So far, most of the studies devoted much attention to the mechanical results of the post-eroded sample rather than microscale variation and stress state during the suffusion process. The researches on the mechanism of particle detachment and its corresponding evolution process are limited. Therefore, the particle detachment mechanism considering different flow directions in the anisotropic stress state during suffusion is investigated in this paper for a bi-disperse granular material thanks to three-dimensional LBM-DEM numerical simulations. A brief introduction of the LBM-DEM scheme and detailed modeling setup for suffusion simulation are given in Section 2. Section 3 gives the results and analysis in the microscopic directional analysis as well as detachment mechanism of suffusion. Finally, Section 4 summarizes the results and presents a 
conclusion of the particle detachment mechanism in anisotropic stress states.

\section{Simulation of suffusion}

\subsection{LBM-DEM method}

A three-dimensional and spatially resolved fluid-solid coupling method based on LBM-DEM is adopted to simulate the suffusion process. Among the coupling methods mentioned in the introduction, LBM-DEM has inherent advantages in terms of explicit formulation and large-scale parallel computing. The open source software LIGGGHTS is selected to solve DEM part [36], while fluid motion is controlled with the open source software Palabos [55]. The fluid solid coupling calculation is achieved by establishing ports in the two open source software. We coded the coupling in $\mathrm{C}++$ based on the work of Seil \& Pirker [56]. The immersed moving boundary (IMB) is adopted because of its superiority over other methods in terms of accuracy and stability [57][58].

We use the D3Q19 model in the LBM, because it possesses a good balance between accuracy and efficiency among other 3D LBM models [57][59]. According to the Bhatnagar-Gross-Krook approximation, the lattice Boltzmann equation is written as [60]:

$$
f_{i}\left(\mathbf{x}+\mathbf{c}_{i} \delta_{t}, t+\delta_{t}\right)-f_{i}(\mathbf{x}, t)=-\frac{1}{\tau}\left[f_{i}(\mathbf{x}, t)-f_{i}^{e q}(\mathbf{x}, t)\right]
$$

where $f_{i}(\mathbf{x}, t)$ denotes the density distribution function whose coordinate is $\mathbf{x}$ directing in the $i^{\text {th }}$ path at time $t$; $\mathbf{c}_{i}$ represents 19 discrete velocity vectors; and $\tau$ is a relaxation coefficient, which controls the stability of LBM simulations.

The equilibrium distribution functions $f_{i}^{\text {eq }}(\mathbf{x}, t)$ in the right side of Eq. (1) is defined as 


$$
f_{i}^{\text {eq }}=w_{i} \rho_{\text {fluid }}\left[1+\frac{\mathbf{c}_{i} \cdot \mathbf{u}_{\text {fluid }}}{c_{\mathrm{s}}^{2}}+\frac{\left(\mathbf{c}_{i} \cdot \mathbf{u}_{\text {fluid }}\right)^{2}}{2 c_{\mathrm{s}}}-\frac{\left|\mathbf{u}_{\text {fluid }}\right|^{2}}{2 c_{\mathrm{s}}^{2}}\right](i=0, \ldots, 18)
$$

where $w_{i}(i=0, \ldots, 18)$ are the weighting factors, $w_{0}=1 / 3, w_{1-6}=1 / 18, w_{7-18}=1 / 36$; $\rho_{\text {fluid }}$ and $\mathbf{u}_{\text {fluid }}$ are the density and velocity of fluid, respectively. The sound speed is taken as $c_{\mathrm{s}}=1 / \sqrt{3}$ in lattice units in the 3D LBM model [61].

According to the transfer method, the fluid velocity, fluid density, and fluid pressure can be calculated at each discretization point from LBM quantities as follows [62][63]:

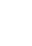

$$
\rho_{\text {fluid }}=\sum_{i=0}^{18} f_{i}
$$

$$
\mathbf{u}_{\text {fluid }}=\frac{1}{\rho_{\text {fluid }}} \sum_{i=0}^{18} \mathbf{c}_{i} f_{i}
$$

$$
p_{\text {fluid }}=c_{\mathrm{s}}^{2} \rho_{\text {fluid }}
$$

Equation 5 reveals that the incompressible flow is satisfied approximately as slightly compressible flow in LBM simulation. To achieve the simulation of the slightly compressible flow, the computational Mach number must fulfill $M a<<1$, which is defined as maximum simulated velocity in the flow divided by sound speed in the fluid [64]. The limitation requires the setting of parameters in LBM, and the relationship between parameters can be described as follows,

$$
v_{\text {fluid }}=c_{s}^{2}\left(\tau-\frac{1}{2}\right) \frac{(\delta x)^{2}}{\delta t}
$$

where $v_{\text {fluid }}$ is the kinematic viscosity of fluid, $\delta x$ is grid spacing, and $\delta t$ is the timestep of LBM. From the perspective of numerical simulation, the commonly used method is to set $\delta x$ and $\tau$ first, then compute $\delta t$ based on the Eq. (6) [64][65]. 
The value of $\delta x$ affects the accuracy of LB calculation and the cost of computational resources. It is evident that the smaller $\delta x$ leads to better simulation accuracy, but it also increases the computational cost. And the relaxation parameter $\tau$ greatly determines the stability of LB calculation, with the requirement $\tau>0.5$ in equation (6). The LB formulation will be more prone to numerical instability when $\tau$ is approaching 0.5 [64][66]. Feng et al. [64][65] discussed in details the choice of these parameters to achieve a satisfying tradeoff between the desired accuracy, reasonable computational cost and numerical stability of the calculation.

In DEM, the spherical particles' displacement is controlled by the Newton's second law of motion [30]:

$$
\begin{array}{r}
m_{i} \mathbf{a}=\mathbf{F}_{\mathrm{c}}+\mathbf{F}_{\text {fluid }} \\
I_{i} \dot{\boldsymbol{\omega}}=\mathbf{T}_{\mathrm{c}}+\mathbf{T}_{\text {fluid }}
\end{array}
$$

where $I_{i}$ is the moment of inertia of particle, $m_{i}$ is the mass of the particle; a is the motion acceleration; $\boldsymbol{\omega}$ is the angular velocity; $\mathbf{F}_{\mathrm{c}}$ are the contact forces between particles and $\mathbf{T}_{\mathrm{c}}$ is corresponding torques provided by particle collision; $\mathbf{F}_{\text {fluid }}$ and $\mathbf{T}_{\text {fluid }}$ are the hydrodynamic force and the corresponding torque provided by the fluid part, respectively. The normal force $\mathbf{F}_{\mathrm{n}}$ and tangential force $\mathbf{F}_{\mathrm{t}}$ between two particles are calculated by the Hertz-Mindlin contact model [67][68]. A rolling resistance is used all along the simulation according to the torque model proposed by Zhou et al [69]. The aim of introducing rolling resistance is to account for non-spherical particle shapes to some extent, the value of rolling friction parameter in this study is the same as those in other DEM studies of suffusion [44][45]. In relation with suffusion, 
the rolling resistance is known to increase the number of small particles involved in force transmission.

Fluid-solid interaction calculations are achieved by adding a collision term $\Omega_{i}^{s}$ to Eq. (1), the govern equation becomes

$$
\begin{gathered}
\left.f_{i}\left(\mathbf{x}+\mathbf{c}_{i} \delta_{t}, t+\delta_{t}\right)-f_{i}(\mathbf{x}, t)=-\frac{1}{\tau}\left[f_{i}(\mathbf{x}, t)-f_{i}^{\mathrm{eq}}(\mathbf{x}, t)\right](1-B)+B \Omega_{i}^{s}\right] \\
\Omega_{i}^{\mathrm{s}}=f_{-i}(\mathbf{x}, t)-f_{-i}^{\mathrm{eq}}\left(\rho_{\text {fluid }}, \mathbf{u}_{\text {fluid }}\right)+f_{i}^{\mathrm{eq}}\left(\rho_{\text {fluid }}, \mathbf{u}_{\mathrm{s}}\right)-f_{i}(\mathbf{x}, t)
\end{gathered}
$$

where $B=\frac{\varepsilon(\tau-0.5)}{(1-\varepsilon)+(\tau-0.5)}$ is a weighting function of the relaxation coefficient $\tau$ and solid ratio $\varepsilon$ of the LBM cell. $\varepsilon=V_{\text {solid }} / V_{\text {cell }}$, and thus, $\varepsilon=0(1)$ yields $B=0(1)$. The subscript $-i$ in the Eq. (10) represents the opposite direction to $i$.

Taking the effect of particle rotation into consideration, the velocity of the solid part $\mathbf{u}_{\mathrm{s}}$ is calculated as [51]

$$
\mathbf{u}_{\mathrm{s}}=\mathbf{u}_{p}+\boldsymbol{\omega}_{p} \times\left[\left(\mathbf{x}+0.5 \mathbf{c}_{i} \delta_{t}\right)-\mathbf{x}_{p}\right]
$$

where $\mathbf{u}_{p}$ and $\boldsymbol{\omega}_{p}$ are translational and angular velocities of solid particle, and $\mathbf{x}_{p}$ is the position of solid particle.

Lastly, the hydrodynamic force $\mathbf{F}_{\text {fluid }}$ and the corresponding hydraulic torque $\mathbf{T}_{\text {fluid }}$ applied by fluid motion can be calculated as:

$$
\begin{gathered}
\mathbf{F}_{\text {fluid }}=\sum_{j=1}^{n} B_{j} \sum_{i=0}^{18} \Omega_{i}^{\mathrm{s}} \mathbf{c}_{i} \\
\mathbf{T}_{\text {fluid }}=\sum_{j=1}^{n}\left[B_{j}\left(\mathbf{x}_{j}-\mathbf{x}_{p}\right) \times \sum_{i=0}^{18} \Omega_{i}^{s} \mathbf{c}_{i}\right]
\end{gathered}
$$

where $n$ is the total number of lattice cells covered by the solid part; $B_{j}$ refer to the weight coverage function in $j$-th lattice cell among $n$ lattice cells.

To achieve a stable DEM simulation, the DEM time step, $\Delta t_{\mathrm{DEM}}$, needs to be 
smaller than a critical value proportional to $\sqrt{m / K}$, where $m$ and $K$ are the mass and stiffness of the particles [70]. For problems in the geotechnical field due to the large stiffness of soils and rocks, the calculation time step length of LBM is larger than DEM [51][71]. Therefore, a sub-cycle method is used to solve the communication between

LBM and DEM computation parts. The implementation of a series of repeated DEM time steps is allowed within a single LBM time step. Particle information in the DEM is transported to the LBM to identify the node occupied by solid in the domain every $N_{\text {sub }}=\delta t / \Delta t_{\text {DEM }}$ DEM cycles [51]. In this study, considering accuracy and computational cost, $N_{\text {sub }}$ is selected as 10 , which has been proposed by Owen et al. from an algorithmic perspective [51] and has also been adopted in previous simulations of suffusion [53][54].

\subsection{Sample generation and pre-stress procedure}

The numerical simulation takes macroscopic fluid direction, hydraulic gradient, and vertical stress levels as factors to conduct research. The schematic figure of the 212 simulation is shown in Fig. 1. 


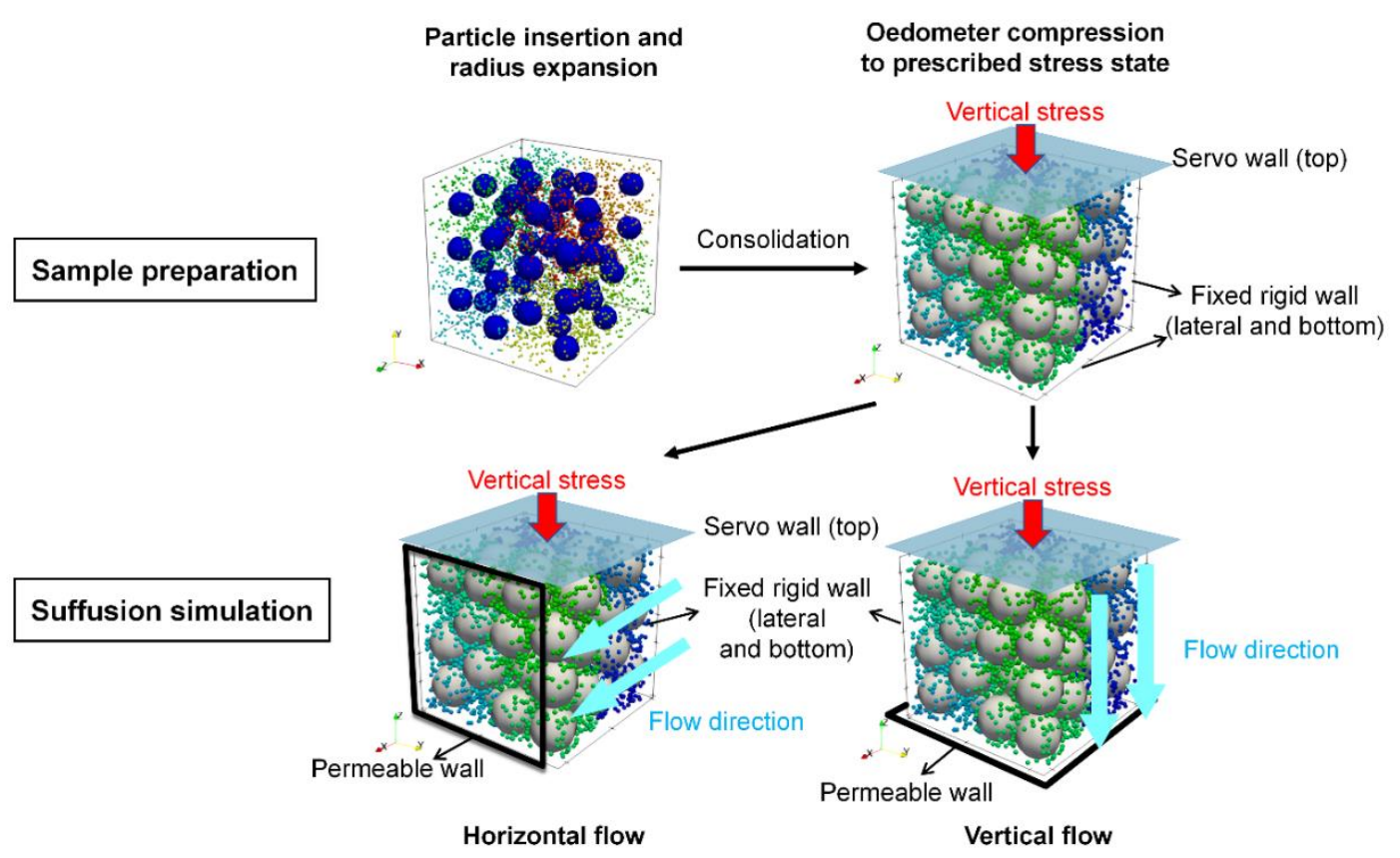

Fig.1 Numerical procedure from sample preparation (radius expansion technique and dry oedometer compression) to suffusion simulations (fully coupled DEM-LBM simulations) for different flow directions. content $(F C)$ of binary mixture is known to be an important parameter that drives the

217 sample's mechanical behavior depending whether the force transmission skeleton is 218 composed of coarse or fine particles. In this paper, $F C$ is set to $30 \%$ which is in the 219 transition region between "underfilled" and "overfilled" configurations [72][2]. In this case, fine and coarse particles are both involved in stress transmission. process. The specific steps are shown in Figure 1. First, a binary packing is randomly inserted in a cubic box. Then, the radius expansion method is used to isotropically 
consolidate the sample to a small stress value and obtain particles with the targeted radius value. After that, the boundaries of the sample are moved to consolidate the sample under an isotropic stress state with mean pressure of $100 \mathrm{kPa}$. This preparation procedure ends with a prepared binary mixture with dimension $0.11 \times 0.11 \times 0.11 \mathrm{~m}$. For the sake of disregarding any boundary effects, the subsequent statistical analyses are only based on the central volume $(0.10 \times 0.10 \times 0.10 \mathrm{~m})$. We emphasize that the sample in our simulations is probably too small to be considered as a representative elementary volume with respect to material constitutive properties (the sample contains only large particles), however, the present study focuses on the micromechanical detachment mechanism, which can still be analyzed in such small samples.

Eventually, the binary packing is compressed vertically to prescribed stress levels with a servo-controlled method in the top boundary, while the lateral walls and the bottom wall are kept fixed (oedometer compression). This results in an anisotropic stress state, the principal compression direction being aligned with the z-axis, referred to as the "vertical" direction (even in the absence of gravity forces). When the equilibrium of the sample is reached under prescribed compressive stress, it will be considered as the end of sample preparation and the beginning of suffusion simulation.

\subsection{Suffusion simulation step}

After generating an anisotropic stress state in the sample, an internal fluid flow is simulated by applying a fluid pressure difference on the sample boundaries in two selected directions ( $x$-axis for a horizontal flow, $z$-axis for a vertical flow). The fluid pressure drop $\Delta p$ applied on the upstream and downstream relates to the hydraulic 
gradient $I$ as $\Delta p=\rho g h I^{2}$. Permeable walls are used in the flow direction while zero flux conditions are imposed in other directions. As shown in Figure 1, the downstream wall is permeable to both the fluid and the small particles to allow for suffusion to occur.

Only small particles are able to escape from the sample through the permeable wall which ensure that the stress state in the sample is kept constant. For the boundary conditions in LBM, pressure boundary conditions are used in the direction of fluid flow and the half-way bounce-back scheme is applied in other wall boundaries (zero flux boundary conditions) [73]. The values of the hydraulic gradient considered in this study are 0.1 and 1.0, and the values of the vertical stress levels are $0.1 \mathrm{MPa}$ and $0.5 \mathrm{MPa}$.

\footnotetext{
2 Note that, since gravity is not taken into account, the hydraulic gradient is simply a dimensionless scaling of the fluid pressure drop.
} 
values in a series of numerical simulation by LBM-DEM [53][65][66][74], especially in the similar simulations of soil erosion in granular filter using LBM-DEM, in which an even smaller value $(\tau-0.5)=5 \times 10^{-7}$ was adopted [53][74]

The three-dimensional simulation in this research is carried out using one node challenging to apply this method to larger size problems without using massive parallelization techniques.

Table 1 The simulations carried out based on various conditions

\begin{tabular}{ccccc}
\hline Conditions & $\begin{array}{c}\text { Vertical stress, } \\
\sigma_{\mathrm{v}}(\mathrm{MPa})\end{array}$ & $\begin{array}{c}\text { Stress ratio, } \\
\eta=q / p\end{array}$ & $\begin{array}{c}\text { Hydraulic gradient, } \\
I\end{array}$ & Flow direction \\
\hline Case 1 & 0.1 & 0.7 & 1.0 & Horizontal \\
Case 2 & 0.5 & 1.1 & 0.1 & Horizontal \\
Case 3 & 0.5 & 1.1 & 1.0 & Horizontal \\
Case 4 & 0.5 & 1.1 & 1.0 & Vertical \\
\hline
\end{tabular}

Table 2 Parameters of the LBM-DEM simulations

\begin{tabular}{llll}
\hline & Parameters & Units & Values \\
\hline \multirow{4}{*}{ DEM } & Particle density, $\rho$ & $\mathrm{kg} / \mathrm{m}^{3}$ & 2600 \\
& Particle number, $N_{\text {coarse }} / N_{\text {fine }}$ & & $60 / 26728$ \\
& Contact model & & Hertz-Mindlin \\
& Young's module, $Y$ & $\mathrm{GPa}$ & 25 \\
& Poisson ratio, $v$ & & 0.3 \\
& Maximum diameter, $d_{\max }$ & $\mathrm{mm}$ & 30 \\
& Minimum diameter, $d_{\min }$ & $\mathrm{mm}$ & 3
\end{tabular}




\begin{tabular}{llll} 
& Particle size ratio & & 10 \\
& Sliding friction, $\mu$ & & 0.5 \\
& Rolling friction, $\mu_{\mathrm{r}}$ & & 0.1 \\
& DEM time step, $\Delta t_{\text {DEM }}$ & $\mathrm{s}$ & $4.45 \times 10^{-8}$ \\
\hline \multirow{3}{*}{ LBM } & Fluid density, $\rho_{\text {fluid }}$ & $\mathrm{kg} / \mathrm{m}^{3}$ & 1000 \\
& Kinematic viscosity, $v_{\text {fluid }}$ & $\mathrm{m}^{2} / \mathrm{s}$ & $1.01 \times 10^{-6}$ \\
& LBM time step, $\delta t$ & $\mathrm{~s}$ & $4.45 \times 10^{-7}$ \\
\hline
\end{tabular}

\section{Results and discussions}

\subsection{Effects of the flow conditions on suffusion intensity}

The suffusion phenomenon under different flow directions is simulated and the evolution of erosion rate and void ratio $e$ in the granular assembly in horizontal and vertical flow directions are compared. The results of $e$ are displayed in the condition $I$ $=1.0$, vertical stress $\sigma_{\mathrm{v}}=0.5 \mathrm{MPa}$ (Case 3 and Case 4) in Figure 2. Obviously, the void ratio $e$ increases, due to the seepage-induced loss of fines. Subsequently, due to the settling and reorganization of coarse particles after the erosion of fine particles $(F C)$, the inter-granular void ratio [76], $e_{e q}=\frac{e+F C}{1-F C}$ is significantly reduced in the vertical flow $^{3}$. This also corresponds to the higher erosion rate in Figure 3 under vertical flow when the hydraulic gradient is the same in both flow directions. A larger erosion ratio compared with $I=0.1$ condition is also achieved when $I=1.0$ in the horizontal flow as

293 shown in Figure 3. The anisotropic stress state is the main reason for the variations in 294 the suffusion process in the vertical and horizontal flow and will be the subject of 295 detailed analysis in the following. In order to quantify the microstructure anisotropy,

\footnotetext{
3 Note that the present intergranular void ratio definition assumes that no fine particles participate to stress transmission, which is not exact for transitional materials. The definition should be updated by considering the non-active fine content only.
} 

erosion are computed. The fabric tensor of contact normal are quantified by the definition proposed by Oda [77]:

$$
\phi_{i j}=\frac{1}{N_{c}} \sum_{c \in N_{c}} n_{i} n_{j}
$$

where $n$ is the unit vector of the contact normal direction, $N_{c}$ is the number of contacts. The fabric tensor of normal contact force can be defined as follows [78]:

$$
\chi_{i j}^{n}=\frac{1}{N_{c}} \sum_{c \in N_{c}} \frac{f^{n} n_{i} n_{j}}{1+a_{k l}^{c} n_{k} n_{l}}
$$
calculate the fabric tensor of contact normal $\left(\phi_{i j}\right)$ and normal contact force $\left(\chi_{i j}^{n}\right)$ in the sample: $\phi_{x x}=0.3232, \phi_{y y}=0.3258, \phi_{z z}=0.3510$ and $\chi_{x x}^{n}=0.1046, \chi_{y y}^{n}=0.1055$, $\chi_{z z}^{n}=0.1349$ (off diagonal terms are negligible).

(a)

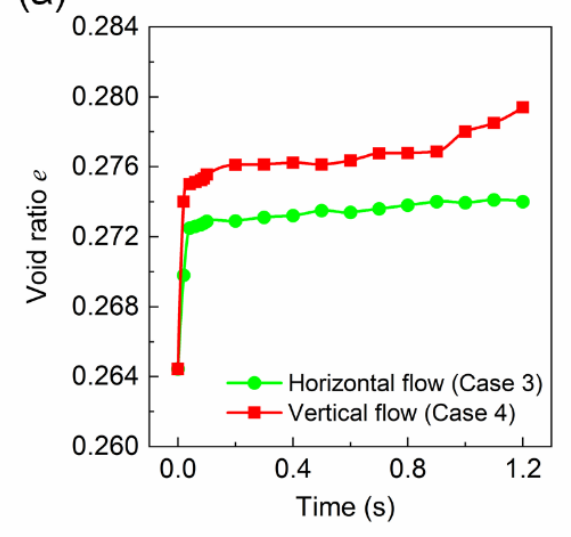

(b)

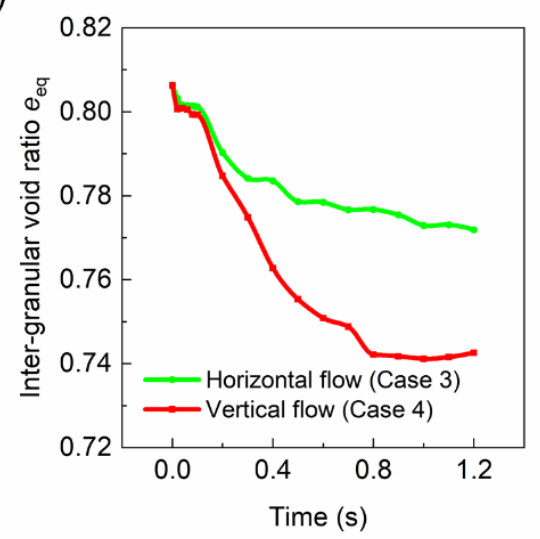

Fig.2 The variation of void ratio, $e$ and inter-granular void ratio $e_{e q}\left(I=1.0, \sigma_{\mathrm{v}}=\right.$ $0.5 \mathrm{MPa}$ ) 


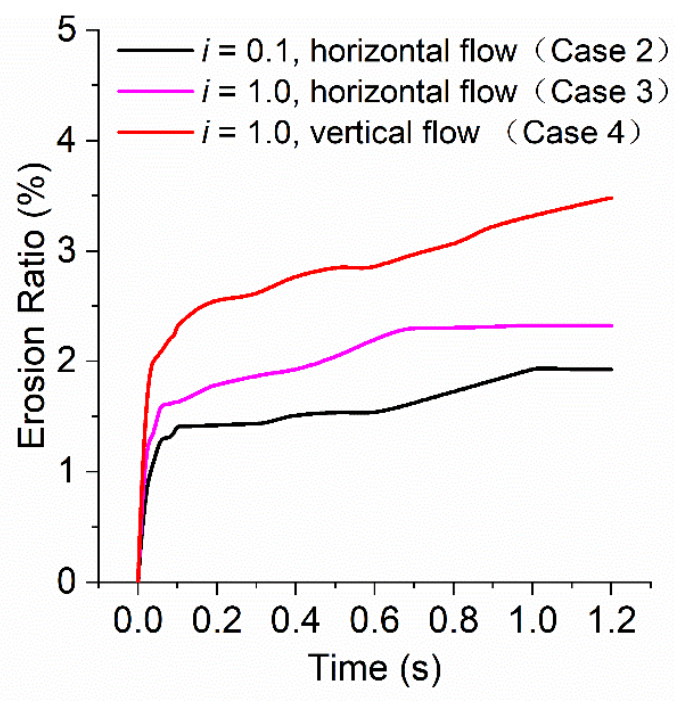

Fig.3 The variation of erosion ratio $m_{\text {eroded }} / m_{\text {total }}\left(\sigma_{\mathrm{v}}=0.5 \mathrm{MPa}\right)$

\subsection{Fluid impact on contact populations}

Based on the two types of particles that come into contact, we can distinguish coarse-coarse contacts (C-C), coarse-fine contacts (C-F), and fine-fine contacts (F-F). The distributions of the number of different contact pairs are summarized in Table 3.

\begin{tabular}{ccccccc}
\hline \multirow{2}{*}{ Pair type } & \multicolumn{3}{c}{ Vertical stress, $\sigma_{\mathrm{v}}=0.5 \mathrm{MPa}$} & \multicolumn{2}{c}{ Vertical stress, $\sigma_{\mathrm{v}}=0.1 \mathrm{MPa}$} \\
\cline { 2 - 7 } & $I=0$ & $I=0.1$ (horizontal) & $I=1.0$ (horizontal) & $I=1.0($ vertical) & $I=0$ & $I=1.0$ (horizontal) \\
\hline Coarse-Coarse & 95 & 95 & 95 & 95 & 94 & 94 \\
Coarse-Fine & 9975 & 9615 & 9228 & 9122 & 9186 & 7765 \\
Fine-Fine & 57495 & 55376 & 53432 & 53306 & 54438 & 47385 \\
\hline
\end{tabular}

Table 3 Distribution of the number of contact pairs under different conditions before $(I=0)$ and after $(I \neq 0)$ applying a fluid flow. 

finding was also observed in [48].

To better analyze this mechanism, the stress tensor computed from contact forces can be split in three terms as in [75],

$$
\sigma_{i j}=\frac{1}{V}\left(\sum_{\mathrm{c} \in \mathrm{c}-\mathrm{c}} f_{i}^{\mathrm{c}-\mathrm{c}} d_{j}^{\mathrm{c}-\mathrm{c}}+\sum_{\mathrm{c} \in \mathrm{c}-\mathrm{f}} f_{i}^{\mathrm{c}-\mathrm{f}} d_{j}^{\mathrm{c}-\mathrm{f}}+\sum_{\mathrm{c} \in \mathrm{f}-\mathrm{f}} f_{i}^{\mathrm{f}-\mathrm{f}} d_{j}^{\mathrm{f}-\mathrm{f}}\right)
$$

where $i$ and $j$ denote either $x, y$, or $z$ to generate the 6 components of the symmetric tensor, $f_{i}$ and $d_{j}$ represent the contact force and branch vector connecting the centers of two contacting particles, respectively. By defining the mean pressure as $p=\frac{1}{3} \sum_{i} \sigma_{i i}$ and the deviatoric stress as $q=\sigma_{z z}-\sigma_{x x}, p$ and $q$ can also be seen as the sum of mean pressure and deviatoric stress computed from the coarse-coarse $(\mathrm{C}-\mathrm{C})$, the coarsefine $(\mathrm{C}-\mathrm{F})$ and the fine-fine $(\mathrm{F}-\mathrm{F})$ contacts. Figure 4 shows the relative contribution of the three contact populations to the mean stress and deviatoric stress under different loading conditions. As exposed in Figure 4ab, C-C contact pairs represent the smallest fraction of the contacts but they transmit most of the stress, especially for deviatoric stress. The contribution of F-F contacts to the deviatoric stress (in Figure 4b) is very small without significant difference whatever the loading conditions. More fine stress is increased from 0.1 MPa to $0.5 \mathrm{MPa}$. As fine particles are eroded by the flow, the stress contribution of C-F and F-F contacts decreases while the contribution of C-C increases. This increase is even larger when the sample is subjected to vertical fluid flow. Despite of the great number in F-F contact pairs shown in Table 3, such contacts do not participate much in stress and have always been weak, corresponding to a great 
342 reduction in pair number with hydraulic loading, which is also one of the reasons for 343 fine particles to be eroded.

(a)

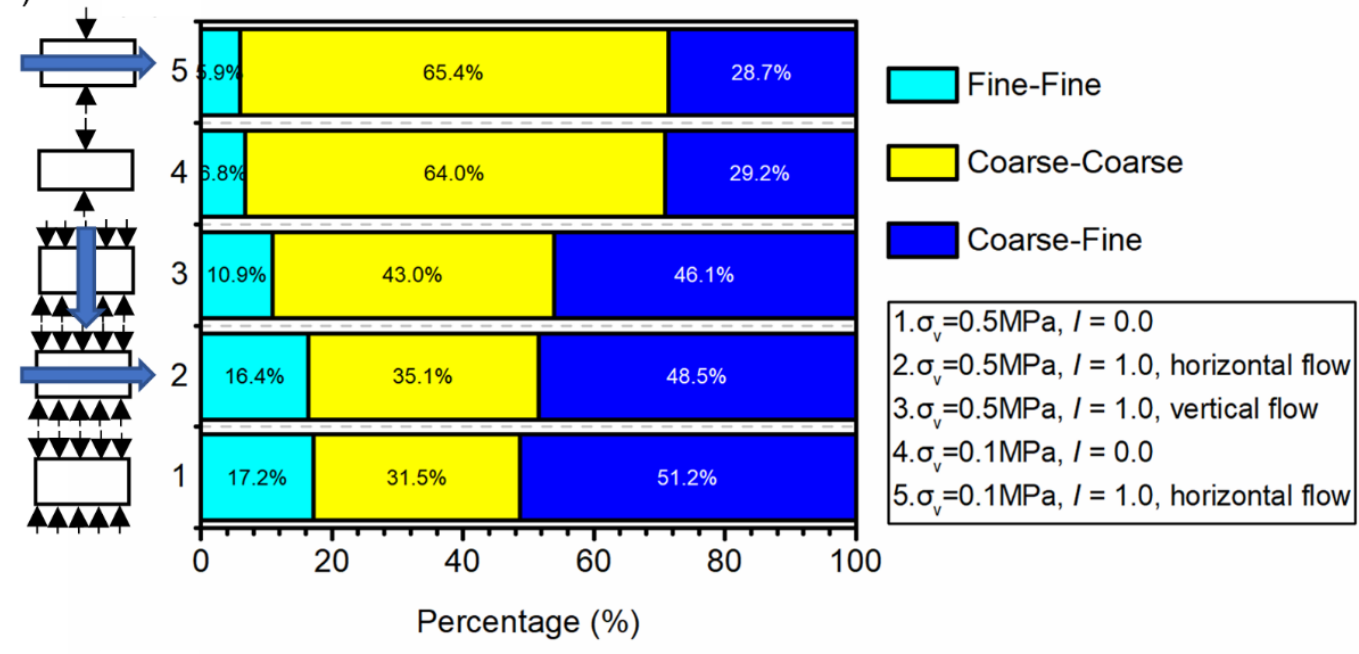

(b)

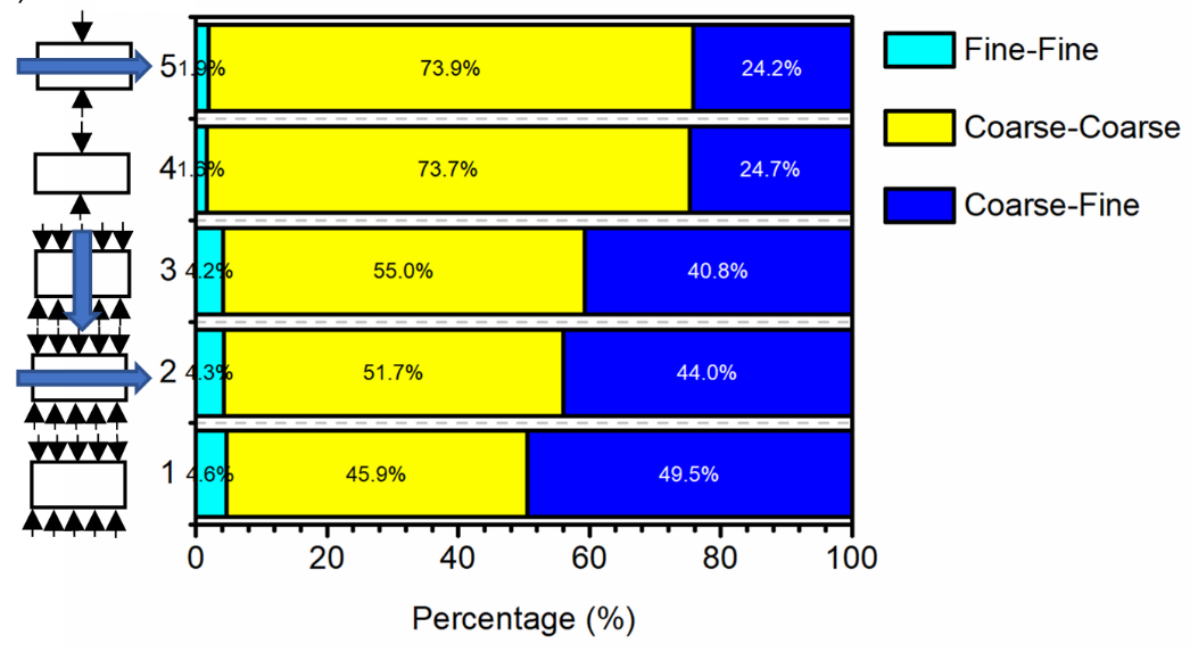

Fig.4 Stress repartition according to the three different types of contact: (a) the distribution of mean stress; (b) the distribution of deviatoric stress. Conceptual schemes (on the left) recall the different loading conditions.

\subsection{Directional porosity and suffusion sensitivity}

To clarify why erosion is stronger in the vertical direction (i.e. when the flow aligns

346 with the stress principal compression direction), we propose a method to compute

347 directional pipe porosity of the initial sample before fluid pressure drop is applied. The 
initial sample selected is in the equilibrium under the loading of the vertical stress $\left(\sigma_{\mathrm{v}}=\right.$ $0.5 \mathrm{MPa}$ ) before applying the hydraulic gradient. Then, rattlers (contact number less than one) are removed to define the effective pore structure. Figure 5 shows a schematic

where $\mathbf{m}_{i}$ is the direction of pipe $i$, and $V_{i}$ is the cylinder volume of pipe $i^{4}$.

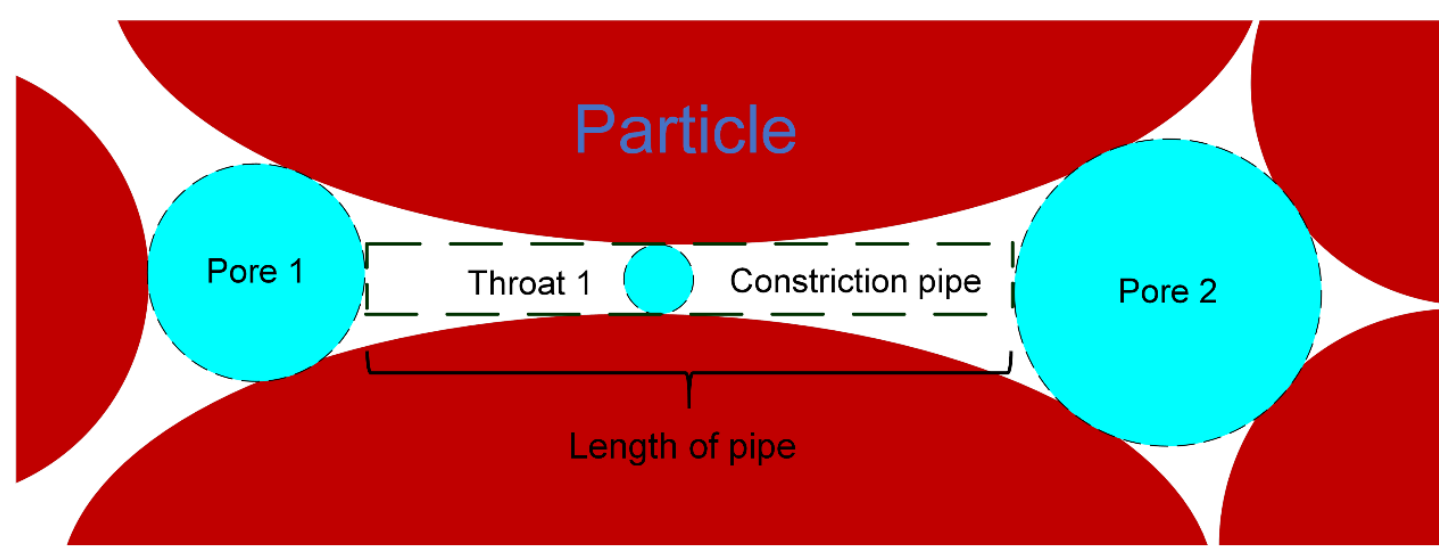

Fig. 5 Schematic image of the constriction pipe in the pore structure

Finally, the computation result of directional pipe porosity when $\sigma_{\mathrm{v}}=0.5 \mathrm{MPa}$ is given below in $x y z$ coordinate system, $z$ being the principal compression direction, as shown in Figure 1.

4 The length of pipe $i$ is defined as the distance between the contact points of pores as shown in the Figure 5. Such length controls the hydraulic conductivity better than the length including also the pore radius. 


$$
\boldsymbol{\varphi}=\left(\begin{array}{lll}
0.5025 & 0.0052 & 0.0062 \\
0.0052 & 0.5031 & 0.0061 \\
0.0062 & 0.0061 & 0.5121
\end{array}\right) * 10^{-3}
$$

362 Note that $\operatorname{Tr}(\varphi)$ is corresponding to the total volume of the pipes divided by the sample

volume. It represents an effective porosity. Because the volume of constriction pipes is just based on the length of the connection channels, disregarding the volume of the pores (see Figure 5), the results of directional pipe porosity is much smaller compare to the sample porosity. It can be seen from the diagonal coefficients that the directional pipe porosity is almost the same in the $x$ and $y$ directions, but the directional porosity is larger along the $z$-axis (the principal compression direction). For eroded particles, large channels are more frequently observed in the $z$-direction. The results of directional porosity are consistent with the sample's directional permeability $\left(K_{x}=0.1499 \mu \mathrm{m}^{2}, K_{y}\right.$ $=0.1501 \mu \mathrm{m}^{2}, K_{z}=0.1661 \mu \mathrm{m}^{2}$ ) computed by Finite-difference method stokes solver (FDMSS) [80].

This difference of permeability between horizontal and vertical directions affects the distribution of fluid forces as displayed in Figure 6 for $t=0.6 \mathrm{~s}$ (half of the simulation time) and a hydraulic gradient of 1 . The mean fluid force value is $0.105 \mathrm{~N}$ for the horizontal flow while it is $0.136 \mathrm{~N}$ for the vertical flow. Although faced with same hydraulic gradient in both flow direction, the directional porosity and permeability lead to a different mean fluid force intensity. In the vertical flow case, the larger permeability results in larger fluid forces, which explains why particle detachment is more likely to occur. In contrast, the maximum proportion of fluid forces in the case of horizontal flow is in the interval [0-0.01] $\mathrm{N}$ which explain why erosion is less pronounced for the 
horizontal flow case.

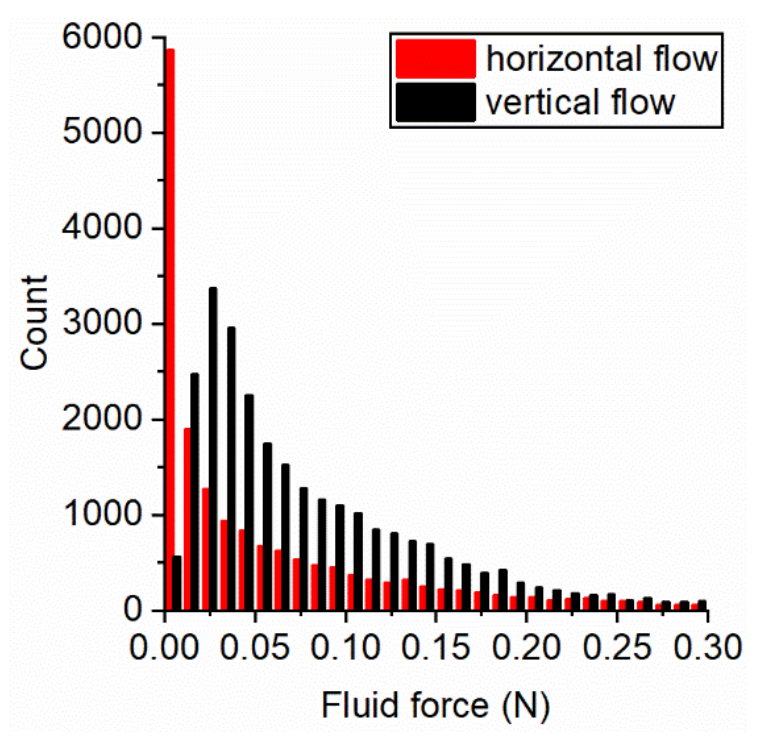

Fig. 6 Distribution of fluid force under different flow direction $\left(I=1.0, \sigma_{\mathrm{v}}=0.5 \mathrm{MPa}\right)$

\subsection{Detachment mechanism of suffusion}

To describe the particle sensitivity to fluid forces, the ratio between the mean contact force and fluid force of the eroded particles is judged by the following index that compare the mean contact force magnitude to the mean fluid force magnitude:

$$
C R=\frac{\frac{1}{N_{\text {contact }}} \sum_{i=1}^{N_{\text {contact }}}\left\|\boldsymbol{F}_{\text {contact }}\right\|}{\left\|\boldsymbol{F}_{\text {fluid }}\right\|}
$$

Particle information in DEM is recorded every 10,000 DEM steps in this simulation. Therefore, the calculation of $C R$ is done every $4.45 \times 10^{-4} \mathrm{~s}$. The time evolution of $C R$ for three typical particles are displayed in Figure 7. The particles detach when $C R=0$. An increase in $C R$ corresponds to a relative increase in contact force, and the movability of the particles is expected to decrease accordingly. The process of monotonous descent in Fig. 7a corresponds to a particle moving continuously without encountering local blockage. Figure 7(b)(c) corresponds to the typical behavior 

several times. Overall, the general decrease in $C R$ index in Figure 7 illustrates that the fluid force gradually dominates the competition with contact.

(a)

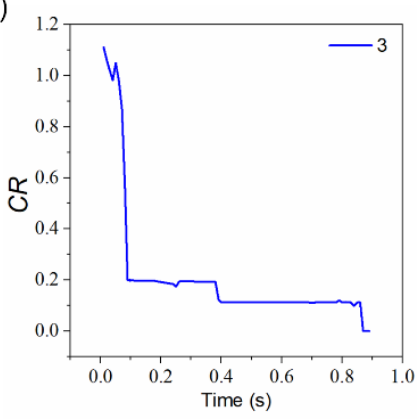

(b)

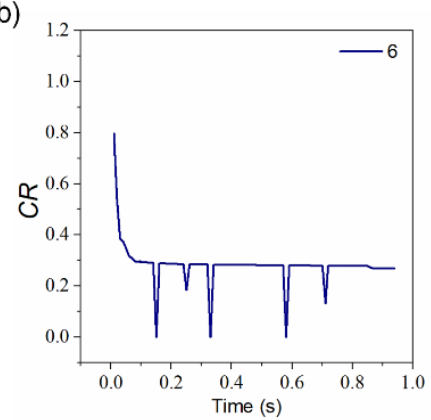

(c)

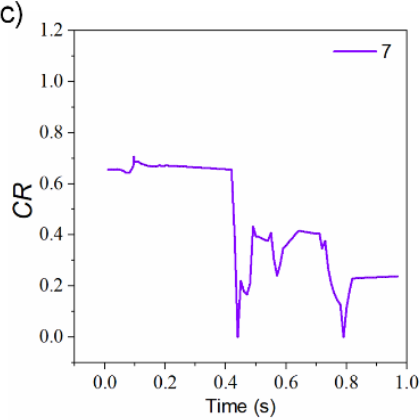

Fig. 7 Three typical $C R$ evolution curves of eroded particles

The statistics for eroded particles below are given at a critical time corresponding

to the moment when the eroded particles are about to lose contact. Hence, the critical time step is not exactly to $C R=0$, but a little earlier. As shown in Figure 8, the sharp drop period of $C R$ is considered as $\Delta t_{c}$, then the red point which is ahead of the point $C R=0$ in time interval $\Delta t_{c}$ is taken as the critical point for subsequent analysis $\left(t_{c}=t_{C R=0^{-}}\right.$ $\Delta t_{c}$ ). Considering the $C R$ evolution of typical particles in Figure $8, \Delta t_{c}$ is estimated once for all and set to $\Delta t_{c}=0.02 \mathrm{~s}$. Since then, the successive contents involving critical time in this article is based on this determination method to obtain the corresponding critical point. 


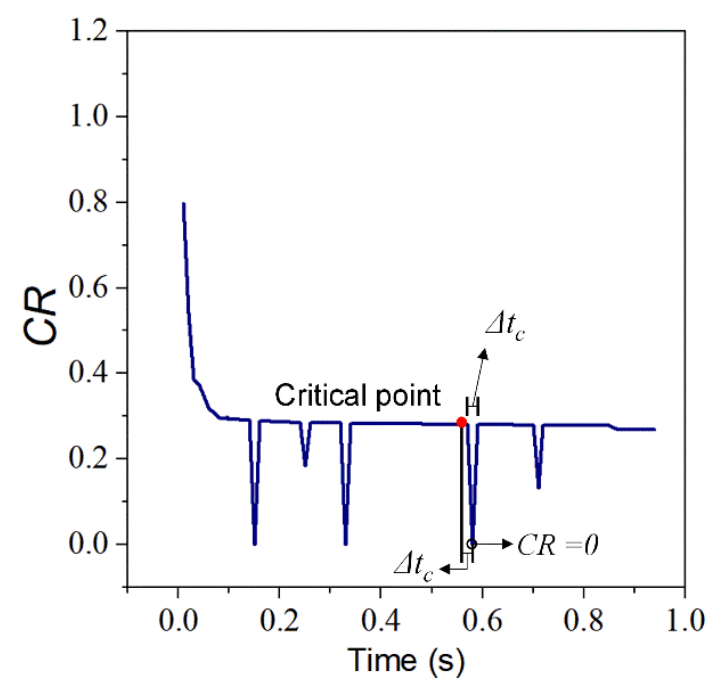

Fig. 8 The determination of critical time $t_{c}$

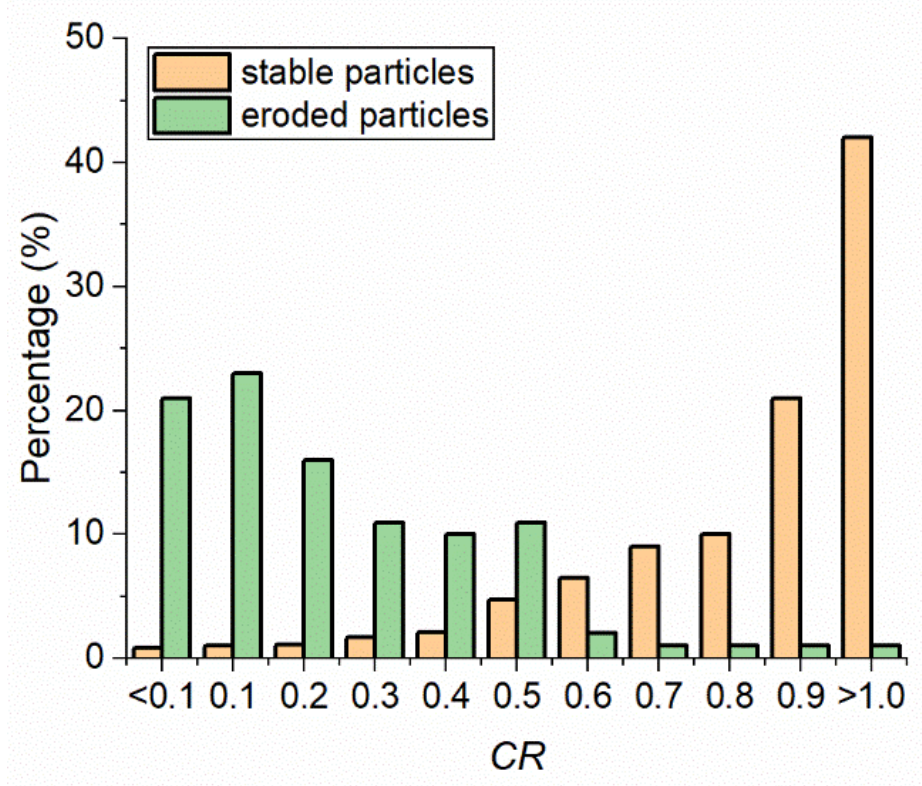

Fig.9 Distribution characteristics of $C R$ stable particles. While the distributions of eroded particles are calculated in the critical

410 time as defined in Figure 8. As shown in Figure 9, most stable particles have a $C R$ 411 magnitude larger than 1.0; whereas most of eroded particles have a CR in the interval 412 [0-0.2]. The dominant position of contact force for stable particles resist the fluid 
erosion, and the influence of the fluid prevails when the eroded particles are going to become free.

In order to get a deeper understanding of the process leading to the vanishing of $C R$ for detached particles, a contact-sliding index $P$ is introduced. This index is design to estimate the potential for sliding of a given particle contact when an additional force (e.g. a fluid force) is applied to the particle in a given direction $\mathbf{m}$ (vertical or horizontal in the present case). Figure 10 illustrate the idealized situation used to derive the $P$ index.

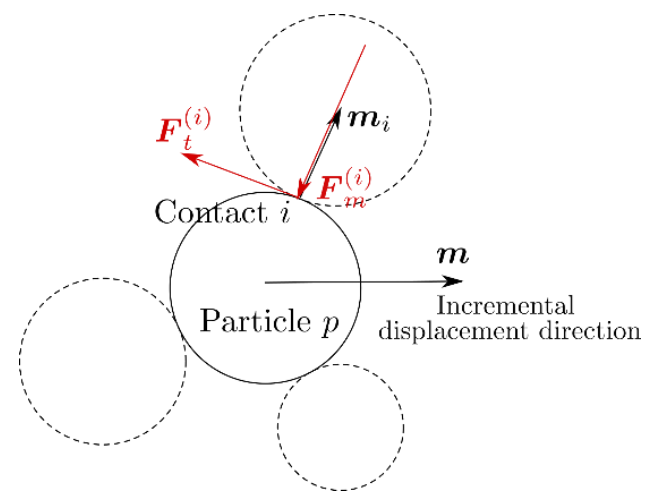

Fig. 10 Idealized configuration to estimate the sliding index $P$ of a given particle contact

We assume that the particle $p$ is at equilibrium and we want to assess the impact of a perturbation force that generate a displacement in direction $\mathbf{m}$. The idea is then to estimate the impact on the normal to tangential force ratio at contact. If this ratio increases, the contact is approaching its sliding limit and the perturbation is deemed to have a destabilization effect on the contact. Based on this analysis, a contact-sliding index $P$ is defined such to indicates whether the contact is going to slide $(P<0)$ or strengthen $(P>0)$ under the action of the fluid force. For the sake of brevity, the detailed derivation of the sliding index $P$ is given in the Appendix I. All computations done, this index is expressed for a contact $i$ belonging to particle $p$ as, 


$$
P^{(i)}(\mathbf{m})=\frac{1}{\tan \varphi^{(i)}} \frac{\left\|\mathbf{F}_{\mathrm{t}}^{(i)}\right\|}{\left\|\mathbf{F}_{\mathrm{m}}^{(i)}\right\|} \|\left[\frac{k_{\mathrm{m}}^{(i)} \mathbf{m} \cdot \mathbf{m}_{i}}{\left\|\mathbf{F}_{\mathrm{m}}^{(i)}\right\|}-\frac{k_{\mathrm{t}}^{(i)} \mathbf{t}_{i} \cdot \mathbf{m}}{\left\|\mathbf{F}_{\mathrm{t}}^{(i)}\right\|}\right]
$$

where $\mathbf{m}$ is the direction of the fluid force acting on particle $p, \mathbf{m}_{i}$ and $\mathbf{t}_{i}$ are the normal and tangential vector of the $i$-th contact of the particle, $\mathbf{F}_{\mathrm{t}}^{(i)}$ and $\mathbf{F}_{\mathrm{m}}^{(i)}$ are the tangential force and contact force of $i$-th contact pair acting on particle $p, k_{\mathrm{m}}^{(i)}$ and $k_{\mathrm{t}}^{(i)}$ are the stiffness in the normal and tangential direction, $\varphi^{(i)}$ is the friction angle of $i$-th contact pair. According to the definition, $P<0$ reflects that the contact pair is going to slide and open if a fluid force in direction $\mathbf{m}$ is applied to the considered particle $p . P^{(i)}$ index is attached to a given contact $i$. In equation (19), two kinds of perturbations contribute to a negative value for $P^{(i)}:$ i) normal unloading of the contact $\left(\mathbf{m} \cdot \mathbf{m}_{\mathbf{i}}<0\right)$, ii) increase in the tangential force $\left(\mathbf{t}_{\mathbf{i}} \mathbf{m}>0\right)$.

In order to construct a detachment index for the particle we define $\Delta=\operatorname{Number}\left(P^{(i)}(\mathbf{m})>0\right)-\operatorname{Number}\left(P^{(i)}(\mathbf{m})<0\right) \quad$ which correspond to the difference between the number of contacts reinforced and weakened under the action of a fluid force in direction $\mathbf{m}$. As a result, a negative value for $\Delta$ is proposed to characterize the overall detachment sensitivity of a given particle subjected to a fluid force in direction m.

Figure 11 shows the $\Delta$ distribution for the eroded particles with different contact number $(\mathrm{CN})$ at critical time (i.e. when the particles are about to lose contact and become free particles). At this time, the calculated value of $\Delta$ is based on the direction of the local fluid force of the individual particles. The distribution of $\Delta$ for the contacts of eroded particles just prior to their detachment well reflects the sliding tendency of contact pairs, because of the large proportion of negative value. Especially for the 


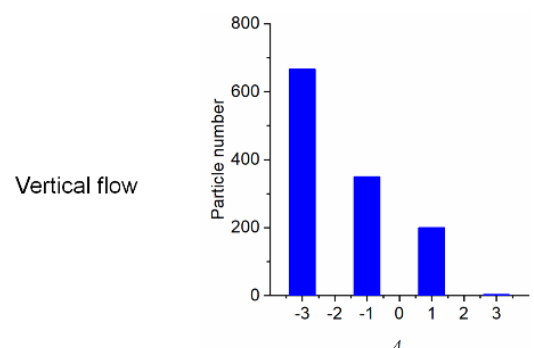

condition when $\mathrm{CN}=5$ in horizontal flow, all contact pairs of the eroded particles show a sliding tendency. Detached particles are thus characterized by a set of contact forces unable to balance the additional force applied by the fluid without sliding or opening.
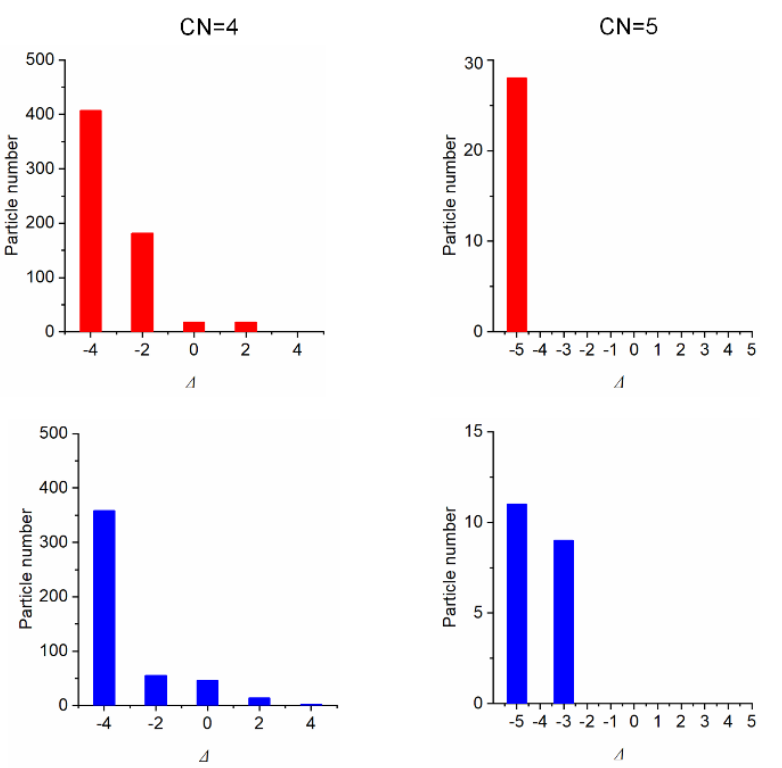

Fig.11 Distribution of $\Delta$ considering different $\mathrm{CN}$ and flow direction

assess which part of the contact sliding potential is simply coming from geometric considerations (decrease in normal force), we also consider the angle between the normal contact vector of eroded particle and macroscopic flow direction at the critical time in Figure 12. The $x$-axis in Figure 12 represents the classification according to the coordination number of eroded particles. The results in Figure 12(a) illustrate that particle detachment often occurs when most of the contacts are perpendicular to the fluid force direction in the horizontal case, which is no longer the case when the fluid align with the principal compression direction (vertical flow case in Figure 12(b)). In addition, for large coordination numbers in horizontal flow in Figure 12(a), the 
proportions of angle larger than 90 degrees from the flow direction become more

467 obvious. This means that, with the increase in the contact number, the direction of the

468 contact normal corresponding to the critical time tends to be closer to the opposite

469 direction of the fluid direction. In vertical flow, the angle distribution is much wider

470 than in the horizontal flow case. In a horizontal flow, the contact state of a typical eroded

471 particle can be described as shown in Figure 13a. The normal vectors of the particle

472 contact are all almost perpendicular to the direction of the fluid; on the contrary, a

473 relatively broad distribution is obtained in vertical flow, as shown in Figure 13b.

474 The absence of correlation between detachment and contact orientation in the vertical flow case could be the signature that particle detachment relies widely on local

476 fluid force fluctuations with respect to the macroscopic direction. As a result, this 477 observation could be interpreted as a smaller sensitivity to particle detachment when 478 the macroscopic flow aligns with the principal stress direction. This is obviously not 479 the case as seen in Figures 2 and 3. As a result, we can conclude that the larger 480 directional pipe porosity, permeability, and fluid force in the vertical direction overwhelm such disadvantage caused by vertical distributed force chains.

(a)

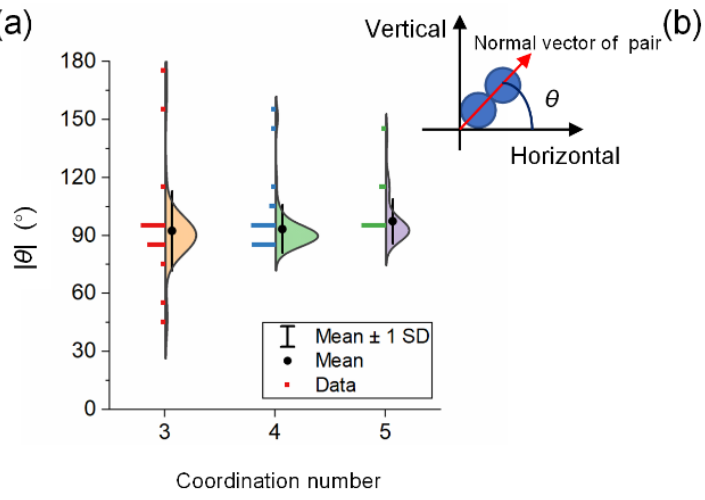

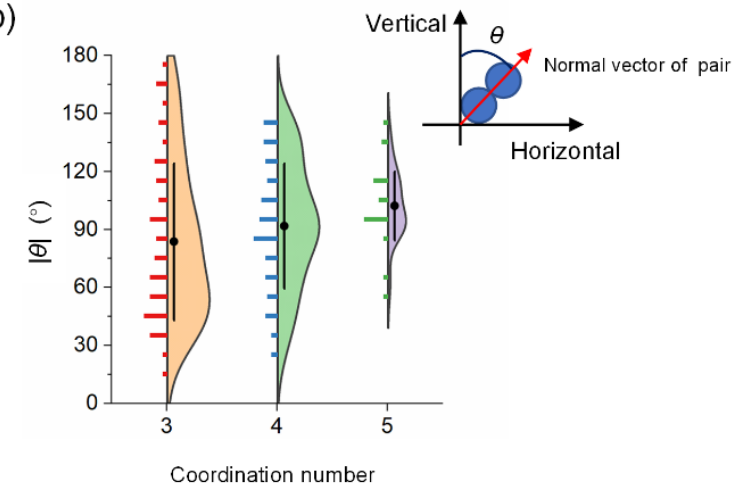


Fig.12 Distribution of angle between flow direction and normal contact vector at critical time for eroded particles: (a) horizontal flow; (b) vertical flow

(a)

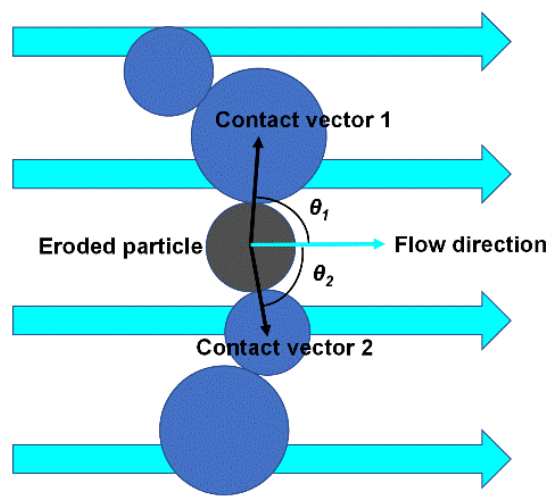

(b)

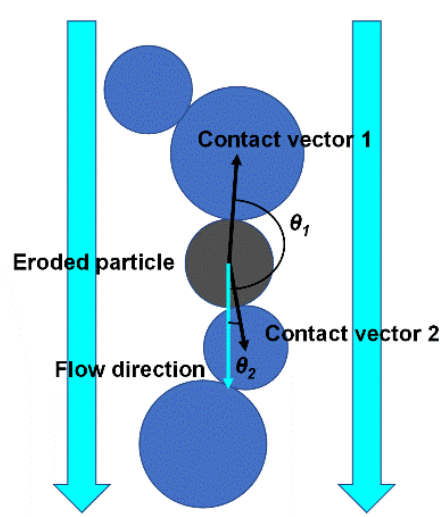

Fig.13 Typical detachment configurations with contact normal directions for (a)

horizontal flow and (b) vertical flow directions. direction.

(a)

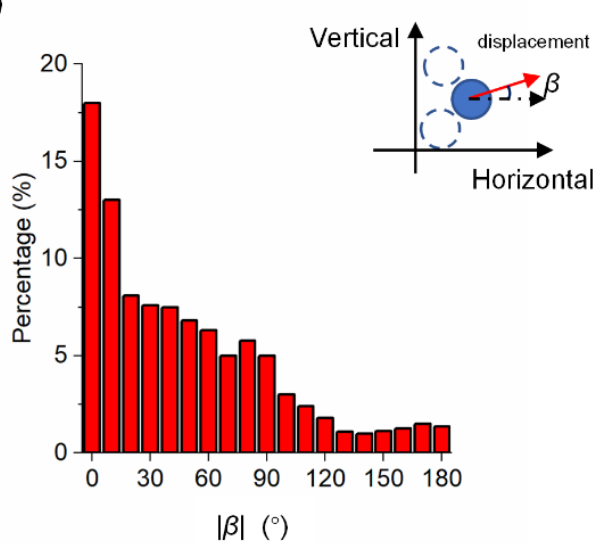

(b)

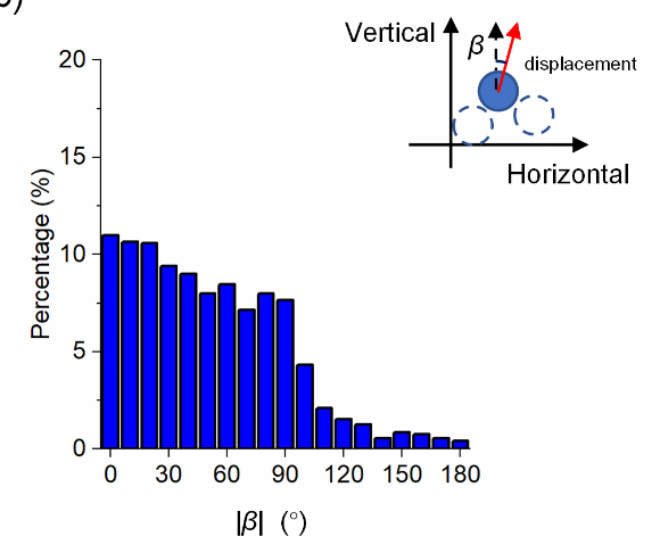

Fig.14 Distribution of angle between flow direction and particle displacement at 
critical time: (a) horizontal flow; (b) vertical flow

An angle of zero means that the displacement is in the same direction of the macroscopic flow (positive $x$-direction in the horizontal case and negative $z$-direction in the vertical case) while an angle of $90^{\circ}$ correspond to a perpendicular direction to the macroscopic flow. Figure 14(a) demonstrates that most eroded particles detached in the direction of macroscopic flow in the horizontal case. A relatively flat distribution is observed in the vertical flow case for angles less than 90 degrees, which support our conjecture. In the vertical flow case, a significant proportion of detachment events occur in the perpendicular direction to the macroscopic flow (in the $x-y$ plane). This feature is linked to the anisotropic contact forces induced by the imposed stress boundary conditions. The greater anisotropy of normal contact force and contact normal in the z-direction (see section 3.1) illustrates the difference of the particle detachment mechanism in different flow direction. This effect also corresponds to the angular distribution when the particles are detached as shown in Figure 12.

\section{Conclusions and outlook}

This paper adopted a three-dimensional coupled LBM-DEM method to simulate the phenomenon of suffusion considering anisotropic stress state. The microscale detachment mechanism is investigated by considering a sliding index and the contact force ratio when the fluid flow is parallel (horizontal) or perpendicular (vertical) to the principal compression direction. The main conclusions can be summarized as follows: 
- Regardless of the initial state, the ratio between the contact force and the fluid force of the eroded particles displays a downward trend over time, reflecting the gradual dominance of the fluid forces, which eventually leads to particle detachment and erosion.

- Compared with horizontal flow, the erosion rate and mean fluid force are greater in vertical flow. This is a consequence of the stress anisotropy, which generates a larger permeability in the direction aligned with the principal stress direction (vertical) and larger fluid forces. The larger directional porosity in the vertical direction also facilitates particle transport and subsequent erosion.

- Based on the comparison between the direction of the fluid force and the direction of the contact force, a contact sliding index $P$ has been proposed to determine whether a given particle contact is going to slide or strengthen under the action of a fluid force. The distribution of $P$ for the contacts of eroded particles just prior to their detachment reflects that fluid-induced sliding dominates.

- The majority of particle migration is directed by the fluid. It follows the flow direction in horizontal flow, but in the vertical flow case, a significant proportion of detachment events occur in the perpendicular direction to the macroscopic flow (in the $x-y$ plane). In this case, where most of the contacts are aligned with the macroscopic direction, particle detachment relies largely on local fluid force fluctuations. This dependence on fluid force fluctuations is expected to reduce the occurrence of particle detachment, but overall, the increase in the fluid forces resulting from larger directional porosity is dominant. To isolate this effect, it 
should be possible to simulate a vertical fluid flow with a reduced hydraulic gradient so that the fluid force magnitude corresponds to the horizontal flow case. Such a simulation is expected to have less erosion than the present horizontal flow case. The conclusion obtained in this study will prove useful for suffusion mitigation in practical applications by assessing the relative orientation between the internal fluid flow and the principal stress direction. On the simulation side, further exploration is needed to be able to simulate larger volumes corresponding to representative elementary volume (REV) for suffusion. A better correlation between fluid force (magnitude and fluctuations) and permeability needs to be established as well in coupled simulations. in the Supercomputing Center of Wuhan University. 


\section{Reference}

554 1. Marot D, Benamar A (2013) Suffusion, Transport and Filtration of Fine Particles in Granular Soil. In: Erosion of Geomaterials

2. Skempton AW, Brogan JM (1994) Experiments on piping in sandy gravels.

Geotechnique 44:449-460

3. Wood DM (2007) The magic of sands - the 20th Bjerrum lecture presented in Oslo, 25 November 20051. Can Geotech J. https://doi.org/10.1139/T07-060

4. Richards KS, Reddy KR (2007) Critical appraisal of piping phenomena in earth dams. Bull Eng Geol Environ. https://doi.org/10.1007/s10064-007-0095-0

5. Foster M, Fell R, Spannagle M (2000) The statistics of embankment dam failures and accidents. Can Geotech J 37:1000-1024

6. Foster M, Fell R, Spannagle M (2000) A method for assessing the relative likelihood of failure of embankment dams by piping. Can Geotech J. https://doi.org/10.1139/t00-029

7. Terzaghi K (1943) Theoretical Soil Mechanics

8. Sellmeijer JB, Koenders MA (1991) A mathematical model for piping. Top Catal. https://doi.org/10.1016/S0307-904X(09)81011-1

9. Schmertmann JH (2000) "No-filter factor of safety against piping through sands." Geotech Spec Publ

10. Kenney TC, Lau D (1985) Internal stability of granular filters. Can Geotech J $22: 215-225$

11. Wan CF, Fell R (2008) Assessing the potential of internal instability and 
suffusion in embankment dams and their foundations. J Geotech geoenvironmental Eng 134:401-407

12. Farahnak Langroudi M, Soroush A, Shourijeh PT (2015) A comparison of micromechanical assessments with internal stability/instability criteria for soils. Powder Technol 276:66-79. https://doi.org/10.1016/j.powtec.2015.02.014

13. Bendahmane F, Marot D, Alexis A (2008) Experimental parametric study of suffusion and backward erosion. J Geotech Geoenvironmental Eng. https://doi.org/10.1061/(ASCE)1090-0241(2008)134:1(57)

14. Chang DS, Zhang LM (2013) Critical Hydraulic Gradients of Internal Erosion under Complex Stress States. J Geotech Geoenvironmental Eng. https://doi.org/10.1061/(ASCE)GT.1943-5606.0000871

15. Moffat R, Fannin JR (2011) A hydromechanical relation governing internal stability of cohesionless soil. Can Geotech J. https://doi.org/10.1139/T10-070

16. Sibille L, Marot D, Sail Y (2015) A description of internal erosion by suffusion and induced settlements on cohesionless granular matter. Acta Geotech. https://doi.org/10.1007/s11440-015-0388-6

17. Li M, Fannin RJ (2008) Comparison of two criteria for internal stability of granular soil. Can Geotech J 45:1303-1309. https://doi.org/10.1139/T08-046

18. Chen C, Zhang LM, Chang DS (2016) Stress-Strain Behavior of Granular Soils Subjected to Internal Erosion. J Geotech Geoenvironmental Eng. https://doi.org/10.1061/(ASCE)GT.1943-5606.0001561

19. Marot D, Rochim A, Nguyen HH, et al (2016) Assessing the susceptibility of 
gap-graded soils to internal erosion: proposition of a new experimental methodology. Nat Hazards 83:. https://doi.org/10.1007/s11069-016-2319-8

20. Moffat R, Fannin RJ, Garner SJ (2011) Spatial and temporal progression of internal erosion in cohesionless soil. Can Geotech J 48:399-412

21. Tomlinson SS, Vaid YP (2000) Seepage forces and confining pressure effects on piping erosion. Can Geotech J. https://doi.org/10.1139/t99-116 characteristics and its mechanical consequences on saturated cohesionless soil. Soils Found. https://doi.org/10.1016/j.sandf.2014.06.024

23. Xiao M, Shwiyhat N (2012) Experimental investigation of the effects of suffusion on physical and geomechanic characteristics of sandy soils. Geotech Test J. https://doi.org/10.1520/GTJ104594

24. Mehdizadeh A, Disfani MM, Evans R, Arulrajah A (2019) Impact of suffusion on the cyclic and post-cyclic behaviour of an internally unstable soil. Geotech Lett. https://doi.org/10.1680/jgele.18.00128

25. Hunter RP, Bowman ET (2018) Visualisation of seepage-induced suffusion and suffosion within internally erodible granular media. Geotechnique. https://doi.org/10.1680/jgeot.17.P.161

26. Nguyen CD, Benahmed N, Andò E, et al (2019) Experimental investigation of microstructural changes in soils eroded by suffusion using X-ray tomography. Acta Geotech 14:749-765

27. Yang J, Yin ZY, Laouafa F, Hicher PY (2020) Three-dimensional 
hydromechanical modeling of internal erosion in dike-on-foundation. Int $\mathbf{J}$ Numer Anal Methods Geomech. https://doi.org/10.1002/nag.3057

28. Bui TA, Gelet R, Marot D (2019) Modelling of internal erosion based on mixture theory: General framework and a case study of soil suffusion. Int J Numer Anal Methods Geomech. https://doi.org/10.1002/nag.2981

29. Rousseau Q, Sciarra G, Gelet R, Marot D (2020) Modelling the poroelastoplastic behaviour of soils subjected to internal erosion by suffusion. Int J Numer Anal Methods Geomech. https://doi.org/10.1002/nag.3014

30. Cundall PA, Strack ODL (1979) A discrete numerical model for granular assemblies. Geotechnique. https://doi.org/10.1680/geot.1979.29.1.47

31. Scholtès L, Hicher P-Y, Sibille L (2010) Multiscale approaches to describe mechanical responses induced by particle removal in granular materials. Comptes Rendus Mécanique 338:627-638

32. Hicher PY (2013) Modelling the impact of particle removal on granular material behaviour. Geotechnique. https://doi.org/10.1680/geot.11.P.020

33. Zhang F, Li M, Peng M, et al (2019) Three-dimensional DEM modeling of the stress-strain behavior for the gap-graded soils subjected to internal erosion. Acta Geotech. https://doi.org/10.1007/s11440-018-0655-4

34. Gu DM, Huang D, Liu HL, et al (2019) A DEM-based approach for modeling the evolution process of seepage-induced erosion in clayey sand. Acta Geotech. https://doi.org/10.1007/s11440-019-00848-0

35. Pirnia P, Duhaime F, Ethier Y, Dubé JS (2020) Hierarchical multiscale 
numerical modelling of internal erosion with discrete and finite elements. Acta Geotech. https://doi.org/10.1007/s11440-020-01009-4

36. Kloss C, Goniva C, Hager A, et al (2012) Models, algorithms and validation for opensource DEM and CFD-DEM. Prog Comput Fluid Dyn an Int J $12: 140-152$

37. Tao J, Tao H (2017) Factors affecting piping erosion resistance: Revisited with a numerical modeling approach. Int J Geomech. https://doi.org/10.1061/(ASCE)GM.1943-5622.0000999

38. Nguyen TT, Indraratna B (2020) The energy transformation of internal erosion based on fluid-particle coupling. Comput Geotech. https://doi.org/10.1016/j.compgeo.2020.103475

39. Cheng K, Wang Y, Yang Q (2018) A semi-resolved CFD-DEM model for seepage-induced fine particle migration in gap-graded soils. Comput Geotech 100:30-51. https://doi.org/10.1016/j.compgeo.2018.04.004

40. Xiong H, Yin ZY, Zhao J, Yang Y (2021) Investigating the effect of flow direction on suffusion and its impacts on gap-graded granular soils. Acta Geotech. https://doi.org/10.1007/s11440-020-01012-9

41. Kanitz M, Grabe J (2021) The influence of the void fraction on the particle migration: A coupled computational fluid dynamics-discrete element method study about drag force correlations. Int J Numer Anal Methods Geomech. https://doi.org/10.1002/nag.3131

42. Liu Y, Wang L, Hong Y, et al (2020) A coupled CFD-DEM investigation of 
suffusion of gap graded soil: Coupling effect of confining pressure and fines content. Int J Numer Anal Methods Geomech. https://doi.org/10.1002/nag.3151

43. Kawano K, Shire T, O'Sullivan C (2018) Coupled particle-fluid simulations of the initiation of suffusion. Soils Found.

44. Hu Z, Zhang Y, Yang Z (2019) Suffusion-induced deformation and microstructural change of granular soils: a coupled CFD-DEM study. Acta Geotech. https://doi.org/10.1007/s11440-019-00789-8

45. Hu Z, Yang ZX, Zhang YD (2020) CFD-DEM modeling of suffusion effect on undrained behavior of internally unstable soils. Comput Geotech. https://doi.org/10.1016/j.compgeo.2020.103692

46. Aboul Hosn R, Sibille L, Benahmed N, Chareyre B (2018) A discrete numerical model involving partial fluid-solid coupling to describe suffusion effects in soils. Comput Geotech 95:30-39. https://doi.org/10.1016/j.compgeo.2017.11.006

47. Wautier A, Bonelli S, Nicot F (2018) Flow impact on granular force chains and induced instability. Phys Rev E. https://doi.org/10.1103/PhysRevE.98.042909

48. Wautier A, Bonelli S, Nicot F (2019) DEM investigations of internal erosion: Grain transport in the light of micromechanics. Int J Numer Anal Methods Geomech. https://doi.org/10.1002/nag.2866

49. Frisch U (1991) Relation between the lattice Boltzmann equation and the Navier-stokes equations. Phys D Nonlinear Phenom. https://doi.org/10.1016/0167-2789(91)90293-I 
685

686

687

688

689

690

691

692

693

694

695

696

697

698

699

700

701

702

703

704

705

706

50. Tran DK, Prime N, Froiio F, et al (2017) Numerical modelling of backward front propagation in piping erosion by DEM-LBM coupling. Eur J Environ Civ Eng. https://doi.org/10.1080/19648189.2016.1248794

51. Owen DRJ, Leonardi CR, Feng YT (2011) An efficient framework for fluidstructure interaction using the lattice Boltzmann method and immersed moving boundaries. Int J Numer Methods Eng. https://doi.org/10.1002/nme.2985

52. Noble DR, Torczynski JR (1998) A Lattice-Boltzmann Method for Partially Saturated Computational Cells. Int J Mod Phys C 09:1189-1201. https://doi.org/10.1142/S0129183198001084

53. Wang M, Feng YT, Pande GN, et al (2017) Numerical modelling of fluidinduced soil erosion in granular filters using a coupled bonded particle lattice Boltzmann method. Comput Geotech 82:134-143.

https://doi.org/10.1016/j.compgeo.2016.10.006

54. Zhou W, Ma Q, Ma G, et al (2020) Microscopic investigation of internal erosion in binary mixtures via the coupled LBM-DEM method. Powder Technol

55. Latt J, Malaspinas O, Kontaxakis D, et al (2020) Palabos: Parallel Lattice Boltzmann Solver. Comput Math with Appl. https://doi.org/10.1016/j.camwa.2020.03.022

56. Seil P, Pirker S (2016) Lbdemcoupling: Open-source power for fluid-particle systems. In: International Conference on Discrete Element Methods. Springer, pp 679-686 
57. Yang GC, Jing L, Kwok CY, Sobral YD (2019) A comprehensive parametric study of LBM-DEM for immersed granular flows. Comput Geotech. https://doi.org/10.1016/j.compgeo.2019.103100

58. Wang M, Feng YT, Owen DRJ, Qu TM (2019) A novel algorithm of immersed moving boundary scheme for fluid-particle interactions in DEM-LBM. Comput Methods Appl Mech Eng. https://doi.org/10.1016/j.cma.2018.12.001

59. Mei R, Shyy W, Yu D, Luo LS (2000) Lattice Boltzmann Method for 3-D Flows with Curved Boundary. J Comput Phys. https://doi.org/10.1006/jcph.2000.6522

60. Bhatnagar PL, Gross EP, Krook M (1954) A model for collision processes in gases. I. Small amplitude processes in charged and neutral one-component systems. Phys Rev. https://doi.org/10.1103/PhysRev.94.511

61. Aidun CK, Clausen JR (2010) Lattice-Boltzmann Method for Complex Flows. Annu Rev Fluid Mech. https://doi.org/10.1146/annurev-fluid-121108-145519

62. Harris S (2004) An introduction to the theory of the Boltzmann equation. Courier Corporation

63. Liboff RL (2003) Kinetic theory: classical, quantum, and relativistic descriptions. Springer Science \& Business Media

64. Feng YT, Han K, Owen DRJ (2007) Coupled lattice Boltzmann method and discrete element modelling of particle transport in turbulent fluid flows: Computational issues. Int J Numer Methods Eng 72:1111-1134. https://doi.org/10.1002/nme.2114 
65. Feng YT, Han K, Owen DRJ (2010) Combined three-dimensional lattice Boltzmann method and discrete element method for modelling fluid-particle interactions with experimental assessment. Int J Numer Methods Eng. https://doi.org/10.1002/nme.2689

66. Ding WT, Xu WJ (2018) Study on the multiphase fluid-solid interaction in granular materials based on an LBM-DEM coupled method. Powder Technol 335:301-314. https://doi.org/10.1016/j.powtec.2018.05.006

67. Hertz H (1882) Ueber die Berührung fester elastischer Körper. J für die reine und Angew Math 1882:156-171

68. Mindlin RD, Mason WP, Osmer TF, Deresiewicz H (1951) Effects of an oscillating tangential force on the contact surfaces of elastic spheres. In: Journal of Applied Mechanics-Transactions of the ASME. ASME-AMER Soc Mechanical Eng 345 E 47TH ST, NEW YORK, NY 10017, p 331

69. Zhou YC, Wright BD, Yang RY, et al (1999) Rolling friction in the dynamic simulation of sandpile formation. Phys A Stat Mech its Appl. https://doi.org/10.1016/S0378-4371(99)00183-1

70. Catherine O, D. BJ (2004) Selecting a suitable time step for discrete element simulations that use the central difference time integration scheme. Eng Comput 21:278-303. https://doi.org/10.1108/02644400410519794

71. He X, Luo LS (1997) Lattice Boltzmann model for the incompressible NavierStokes equation. J Stat Phys

72. Shire T, O'Sullivan C, Hanley KJ, Fannin RJ (2014) Fabric and Effective 

Eng 140:04014072. https://doi.org/10.1061/(ASCE)GT.1943-5606.0001184

73. Ziegler DP (1993) Boundary conditions for lattice Boltzmann simulations. J Stat Phys. https://doi.org/10.1007/BF01049965

74. Wang M, Feng YT, Pande GN, Zhao TT (2018) A coupled 3-dimensional

75. Zhou W, Wu W, Ma G, et al (2018) Undrained behavior of binary granular mixtures with different fines contents. Powder Technol 340:139-153. https://doi.org/10.1016/j.powtec.2018.09.022

76. Thevanayagam S, Mohan S (2000) Intergranular state variables and stressstrain behaviour of silty sands. Geotechnique. https://doi.org/10.1680/geot.2000.50.1.1

77. Oda M (1982) Fabric tensor for discontinuous geological materials. Soils Found 22:96-108

78. Sitharam TG, Vinod JS, Ravishankar B V (2009) Post-liquefaction undrained monotonic behaviour of sands: experiments and DEM simulations. Géotechnique 59:739-749

79. Dong H, Blunt MJ (2009) Pore-network extraction from micro-computerizedtomography images. Phys Rev E - Stat Nonlinear, Soft Matter Phys. https://doi.org/10.1103/PhysRevE.80.036307 
773 80. Gerke KM, Vasilyev R V., Khirevich S, et al (2018) Finite-difference method Stokes solver (FDMSS) for 3D pore geometries: Software development, validation and case studies. Comput Geosci. https://doi.org/10.1016/j.cageo.2018.01.005

777

778

779 


\section{Appendix A}

781

782

783

784

785

786

\section{Definition of a sliding index for a particle contact}

Let us consider a given contact $i$ of a particle $p$ with normal direction $\mathbf{m}_{i}$. At contact $i$, the neighboring particle applies a contact force on particle $p$ that can be decomposed into normal and tangential components $\mathbf{F}_{\mathbf{m}}^{(i)}$ and $\mathbf{F}_{\mathrm{t}}^{(i)}$ respectively. We assume that the particle $p$ is at equilibrium and we want to assess the impact of a perturbation force that generate a displacement $\delta \mathbf{u}$ in direction $\mathbf{m}$. While this force is applied on particle $p$, we also assume that the neighboring particles do not move. This configuration is illustrated in the following Figure.

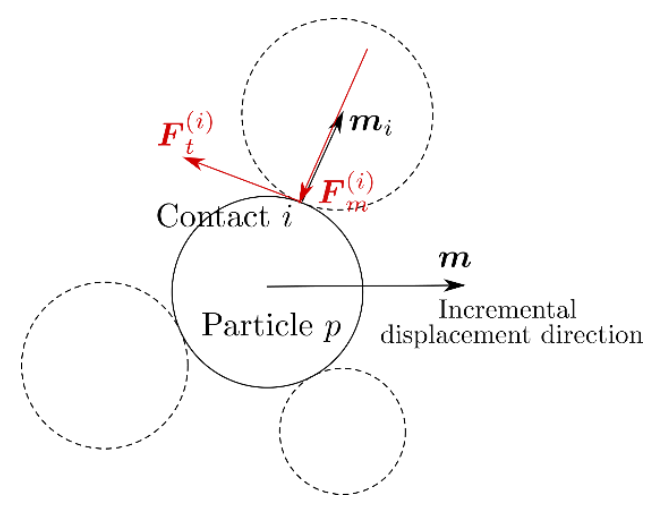

Fig. A.1 Idealized configuration to estimate the sliding index $P$ of a given particle contact

The normal and tangential displacement in the direction of one exist contact pair $\mathbf{u}_{\mathrm{m}}^{(i)}, \mathbf{u}_{\mathrm{t}}^{(i)}$ can be calculated by

$$
\delta \mathbf{u}_{\mathrm{m}}^{(i)}=\left(\delta \mathbf{u} \cdot \mathbf{m}_{i}\right) \mathbf{m}_{i}
$$

$$
\delta \mathbf{u}_{\mathrm{t}}^{(i)}=\left(\mathbf{m}_{i} \wedge \delta \mathbf{u}\right) \wedge \mathbf{m}_{i}
$$

$\delta \mathbf{u}$ is the displacement in the direction of unbalanced force. An elastic contact

$$
\delta \mathbf{F}_{\mathrm{m}}^{(i)}=-k_{\mathrm{m}}^{(i)} \delta \mathbf{u}_{\mathrm{m}}^{(i)}
$$


We define the normalized distance to sliding of a contact according to the friction angle $\varphi$ :

799

$$
\mathrm{d}_{\mathrm{p}}^{(i)}=\frac{\tan \varphi^{(i)}-\frac{\left\|\mathbf{F}_{\mathrm{t}}^{(i)}\right\|}{\left\|\mathbf{F}_{\mathrm{m}}^{(i)}\right\|}}{\tan \varphi^{(i)}} \quad \mathrm{d}_{\mathrm{p}}^{(i)} \in[0,1]
$$

When tangential force $\mathbf{F}_{\mathrm{t}}^{(i)}$ become zero, $\mathrm{d}_{\mathrm{p}}^{(i)}$ is 1 corresponding to no sliding; $801 \quad$ while $\tan \varphi^{(i)}=\frac{\left\|\mathbf{F}_{\mathrm{t}}^{(i)}\right\|}{\left\|\mathbf{F}_{\mathrm{m}}^{(i)}\right\|}, \mathrm{d}_{\mathrm{p}}^{(i)}$ is 0 which can be considered as critical state of sliding.

$$
\delta \mathrm{d}_{\mathrm{p}}^{(i)}=\frac{\tan \varphi^{(i)}-\frac{\left\|\mathbf{F}_{\mathrm{t}}^{(i)}+\delta \mathbf{F}_{\mathrm{t}}^{(i)}\right\|}{\left\|\mathbf{F}_{\mathrm{m}}^{(i)}+\delta \mathbf{F}_{\mathrm{m}}^{(i)}\right\|}-\tan \varphi^{(i)}+\frac{\left\|\mathbf{F}_{\mathrm{t}}^{(i)}\right\|}{\left\|\mathbf{F}_{\mathrm{m}}^{(i)}\right\|}}{\tan \varphi^{(i)}}
$$

$$
=\frac{1}{\tan \varphi^{(i)}} \| \frac{\left\|\mathbf{F}_{\mathrm{t}}^{(i)}\right\|}{\left\|\mathbf{F}_{\mathrm{m}}^{(i)}\right\|} \times\left[1-\frac{\| \frac{\mathbf{F}_{\mathrm{t}}^{(i)}}{\left\|\mathbf{F}_{\mathrm{t}}^{(i)}\right\|}+\frac{\delta \mathbf{F}_{\mathrm{t}}^{(i)}}{\left\|\mathbf{F}_{\mathrm{t}}^{(i)}\right\| \|}}{\left.\| \frac{\mathbf{F}_{\mathrm{m}}^{(i)}}{\left\|\mathbf{F}_{\mathrm{m}}^{(i)}\right\|}+\frac{\delta \mathbf{F}_{\mathrm{m}}^{(i)}}{\left\|\mathbf{F}_{\mathrm{m}}^{(i)}\right\| \|}\right]}\right]
$$

$$
\frac{1}{\| \frac{\mathbf{F}_{\mathrm{m}}^{(i)}}{\left\|\mathbf{F}_{\mathrm{m}}^{(i)}\right\|}+\frac{\delta \mathbf{F}_{\mathrm{m}}^{(i)}}{\left\|\mathbf{F}_{\mathrm{m}}^{(i)}\right\| \|}}=\frac{1}{\left\|-\mathbf{m}_{i}-k_{\mathrm{m}}^{(i)} \frac{\delta \mathbf{u} \cdot \mathbf{m}_{i}}{\left\|\mathbf{F}_{\mathrm{m}}^{(i)}\right\|} \mathbf{m}_{i}\right\|}=1-k_{\mathrm{m}}^{(i)} \frac{\delta \mathbf{u} \cdot \mathbf{m}_{i}}{\left\|\mathbf{F}_{\mathrm{m}}^{(i)}\right\|}=1+\frac{\delta \mathbf{F}_{\mathrm{m}}^{(i)}}{\left\|\mathbf{F}_{\mathrm{m}}^{(i)}\right\|}
$$

Also, we can easily derive that

$$
\begin{aligned}
& \|x+d x\|^{2}=\|x\|^{2}+2 x \cdot d x+o\left(\|d x\|^{2}\right) \\
& \|x+d x\|=\|x\| \sqrt{1+\frac{2 x \cdot d x}{\|x\|^{2}}}=\|x\|\left(1+\frac{x \cdot d x}{\|x\|^{2}}\right)
\end{aligned}
$$

Then the numerator part can also be simplified, 


$$
\left\|\frac{\mathbf{F}_{\mathrm{t}}^{(i)}}{\left\|\mathbf{F}_{\mathrm{t}}^{(i)}\right\|}+\frac{\delta \mathbf{F}_{\mathrm{t}}^{(i)}}{\left\|\mathbf{F}_{\mathrm{t}}^{(i)}\right\|}\right\|=1+\frac{\mathbf{F}_{\mathrm{t}}^{(i)} \delta \mathbf{F}_{\mathrm{t}}^{(i)}}{\left\|\mathbf{F}_{\mathrm{t}}^{(i)}\right\|^{2}}
$$

Finally, we can obtain the following formula,

$$
\delta \mathrm{d}_{\mathrm{p}}^{(i)}=\frac{1}{\tan \varphi^{(i)}} \frac{\left\|\mathbf{F}_{\mathrm{t}}^{(i)}\right\|}{\left\|\mathbf{F}_{\mathrm{m}}^{(i)}\right\|}\left[1-\left(1+\frac{\delta \mathbf{F}_{\mathrm{m}}^{(i)}}{\left\|\mathbf{F}_{\mathrm{m}}^{(i)}\right\|}\right)\left(1+\frac{\mathbf{F}_{\mathrm{t}}^{(i)} \cdot \delta \mathbf{F}_{\mathrm{t}}^{(i)}}{\left\|\mathbf{F}_{\mathrm{t}}^{(i)}\right\|^{2}}\right)\right]
$$

$$
=\frac{1}{\tan \varphi^{(i)}} \frac{\left\|\mathbf{F}_{\mathrm{t}}^{(i)}\right\|}{\left\|\mathbf{F}_{\mathrm{m}}^{(i)}\right\|}\left[-\frac{\delta \mathbf{F}_{\mathrm{m}}^{(i)}}{\left\|\mathbf{F}_{\mathrm{m}}^{(i)}\right\|}-\frac{\mathbf{F}_{\mathrm{t}}^{(i)} \cdot \delta \mathbf{F}_{\mathrm{t}}^{(i)}}{\left\|\mathbf{F}_{\mathrm{t}}^{(i)}\right\|^{2}}\right]
$$

We build the partial differential equation between $\mathrm{d}_{\mathrm{p}}^{(i)}$ and displacement in the unbalanced force direction,

$$
\frac{\delta \mathrm{d}_{\mathrm{p}}^{(i)}}{\delta \mathrm{u}}(\mathbf{m})=\frac{1}{\tan \varphi^{(i)}} \frac{\left\|\mathbf{F}_{\mathrm{t}}^{(i)}\right\|}{\left\|\mathbf{F}_{\mathrm{m}}^{(i)}\right\|}\left[\frac{k_{\mathrm{m}}^{(i)} \mathbf{m} \cdot \mathbf{m}_{i}}{\left\|\mathbf{F}_{\mathrm{m}}^{(i)}\right\|}-\frac{\mathbf{t}_{i} \cdot\left(k_{\mathrm{t}}^{(i)}\left(\mathbf{m}_{i} \wedge \mathbf{m}\right) \wedge \mathbf{m}_{i}\right)}{\left\|\mathbf{F}_{\mathrm{t}}^{(i)}\right\|}\right]
$$

Owing to that

$$
\mathbf{t}_{i}=-\frac{\mathbf{F}_{\mathrm{t}}^{(i)}}{\left\|\mathbf{F}_{\mathrm{t}}^{(i)}\right\|}
$$

$$
\left(\mathbf{m}_{i} \wedge \mathbf{m}\right) \wedge \mathbf{m}_{i}=\left(\mathbf{m}_{i} \cdot \mathbf{m}_{i}\right) \cdot \mathbf{m}-\left(\mathbf{m} \cdot \mathbf{m}_{i}\right) \cdot \mathbf{m}_{i}=\mathbf{m}-\left(\mathbf{m} \cdot \mathbf{m}_{i}\right) \cdot \mathbf{m}_{i}
$$

$$
\mathbf{t}_{i} \cdot \mathbf{m}_{i}=0
$$

Finally, it comes to the conclusion that,

$$
\frac{\delta \mathrm{d}_{\mathrm{p}}^{(i)}}{\delta \mathrm{u}}(\mathbf{m})=\frac{1}{\tan \varphi^{(i)}} \frac{\left\|\mathbf{F}_{\mathrm{t}}^{(i)}\right\|}{\left\|\mathbf{F}_{\mathrm{m}}^{(i)}\right\|}\left[\frac{k_{\mathrm{m}}^{(i)} \mathbf{m} \cdot \mathbf{m}_{i}}{\left\|\mathbf{F}_{\mathrm{m}}^{(i)}\right\|}-\frac{k_{\mathrm{t}}^{(i)} \mathbf{t}_{i} \cdot \mathbf{m}}{\left\|\mathbf{F}_{\mathrm{t}}^{(i)}\right\|}\right]
$$

We ended up writing it as follows:

$$
P^{(i)}(\mathbf{m})=\frac{1}{\tan \varphi^{(i)}} \frac{\left\|\mathbf{F}_{\mathrm{t}}^{(i)}\right\|}{\left\|\mathbf{F}_{\mathrm{m}}^{(i)}\right\|}\left[\frac{k_{\mathrm{m}}^{(i)} \mathbf{m} \cdot \mathbf{m}_{i}}{\left\|\mathbf{F}_{\mathrm{m}}^{(i)}\right\|}-\frac{k_{\mathrm{t}}^{(i)} \mathbf{t}_{i} \cdot \mathbf{m}}{\left\|\mathbf{F}_{\mathrm{t}}^{(i)}\right\|}\right]
$$

If the incremental displacement $\mathbf{m}$ is positively collinear with $\mathbf{m}_{\mathbf{i}}$, then it generates an increase in the normal force (particle interpenetration increases). Therefore, the considered contact is getting away from the sliding condition which corresponds to $P>0$. 
830 For the opposite direction $-\mathbf{m}_{\mathbf{i}}$, particle interpenetration decreases which increases the 831 risk of sliding $(P<0)$.

If the incremental displacement $\mathbf{m}$ is positively collinear with $\mathbf{t}_{\mathbf{i}}$ (the opposite direction to the tangential force $\mathbf{F}_{\mathrm{t}}^{(i)}$ ), the tangential displacement between the two particles will increase, so as the tangential force magnitude. Therefore, the considered contact is approaching the sliding condition which corresponds to $P<0$. For the opposite direction $-\mathbf{t}_{\mathrm{i}}$, the tangential force decreases which decreases the risk of sliding $(P>0)$. For arbitrary directions, the sign of $P(\mathbf{m})$ tells whether contact $i$ is getting closer or not to sliding. Note that this index does not tell which perturbation magnitude is necessary to make the contact slide. Also, note that the sign of the index is attached to

$$
\Delta=\operatorname{Number}\left(P^{(i)}(\mathbf{m})>0\right)-\operatorname{Number}\left(P^{(i)}(\mathbf{m})<0\right)
$$

